\title{
Effects of Organic Acids on the Chemotaxis Profiles and Biocontrol Traits of Antagonistic Bacterial Endophytes Against Root-Rot Disease in Panax Notoginseng
}

\section{Li Ma}

Yunnan University

Wu-Qin Wang

Yunnan University

Rui Shi

Yunnan University

Xue-Mei Zhang

Yunnan University

Xin Li

Yunnan University

Yu-Sen Yang

Yunnan University

Ming He Mo ( $\square$ minghemo@163.com )

Yunnan University

\section{Research Article}

Keywords: Biocontrol traits, Chemotactic antagonistic endophytic bacteria, Chemotaxis profile, Organic acids, Panax notoginseng, Promotion effect.

Posted Date: April 27th, 2021

DOI: https://doi.org/10.21203/rs.3.rs-436794/v1

License: (c) (1) This work is licensed under a Creative Commons Attribution 4.0 International License. Read Full License 


\section{Abstract}

Understanding the role of chemotaxis in ecological interactions between plants and microbes in the rhizosphere is necessary to optimize biocontrol strategies targeting plant soil-borne diseases. Therefore, we examined and profiled the antagonistic endophytic bacteria (AEB) population with chemotaxis potential in the medicinal plant Panax notoginseng using a cheA gene-based approach coupled with $16 \mathrm{~S}$ rRNA sequencing. Phylogenetic analysis of the chemotactic AEB (CAEB) community in P. notoginseng enabled the identification of 56 CAEB strains affiliated with 30 species of Actinobacteria, Firmicutes, and Proteobacteria; Actinobacteria, especially Bacillus, were predominant. We then systematically quantified the chemotactic response profiles of CAEB toward five organic acid (OA) attractants: citric acid (CA), fumaric acid (FA), malic acid (MA), oxalic acid (OX), and succinic acid (SA). Further hierarchical cluster analysis revealed that the chemotaxis of CAEB to the same attractant exhibited different patterns among not only genera but also species and even strains of the same species. Following chemotaxis and hierarchical analysis, we selected the strongest chemoattractant, fumaric acid (FA), as the target for evaluating the effects of OAs on the representative CAEB strain Bacillus amyloliquefaciens subsp. plantarum YP1. Application of FA significantly stimulated the chemotaxis ability and growth of YP1, and increased the transcript levels of $c h e A$ and biocontrol-related genes in YP1. This is the first study to characterise the diversity of chemotaxis profiles toward OAs in natural bacterial assemblages of $P$. notoginseng and to highlight how FA promotes the biocontrol-related traits of $P$. notoginseng-associated CAEB.

\section{Introduction}

Panax notoginseng (Burk.) F. H. Chen (Araliaceae) is a well-known traditional Chinese medicinal herb that has been cultivated in southwestern China for more than 400 years (Guo et al. 2010). Extensive pharmacological studies have shown that $P$. notoginseng and its active ingredients have many effects on the blood system, cardiovascular system, brain, vascular system, nervous system, metabolism, and immune regulation-their specific affects include anti-arrhythmia, anti-cerebral ischemia, anti-platelet aggregation and thrombosis, anti-oxidation, anti-tumor, anti-atherosclerosis, improving hemodynamics, and regulating blood lipid (Sha et al. 2018; Xu et al. 2019). High planting density, a long growth period, and shade and humid planting conditions provide a favorable environment for a number of soil-borne pathogens to survive (Chen et al. 2001; Wang et al. 1998). The most destructive soil-borne disease in the $P$. notoginseng-growing areas of China is root-rot disease (RRD), which is caused by bacteria, fungal pathogens, and parasitic nematodes alone or simultaneously, and results in a serious reduction in the yield and quality of its raw active ingredients (Mao et al. 2013; Miao et al. 2006). RRD is very difficult to control, mainly because of the complicated interaction among different pathogens (Luo et al. 1997); it is therefore desirable to replace chemicals with biocontrol agents (BCAs) that are safe and environmentally friendly whenever possible.

Endophytic bacteria are an essential part of the plant microbiome and may have a competitive advantage over rhizospheric bacteria because they live in plant tissue without having any detrimental impact on the 
host plant. Therefore, their re-introduction does not affect the indigenous bacterial population within the host (Khare et al. 2018). Thus, they have become the most attractive and potentially important BCAs against soil-borne diseases (De Silva et al. 2019). Our lab has demonstrated bacterial endophytes of $P$. notoginseng have antagonistic properties against multiple pathogens-to be potential BCA candidates against RRD in P. notoginseng (Ma et al. 2013). Nonetheless, the exploitation of endophytic inoculants as BCAs has been hampered by inconsistent performance of endophytic bacteria at the field scale (Barret et al. 2011; Raaijmakers et al. 2009). As a result of such variation, a successful rhizosphere interaction with plants has been recognized as a prerequisite for the biocontrol efficacy of the inoculant strain against soil-borne pathogens (Abdallah et al. 2018; Schreiter et al. 2018). Therefore, it is imperative to attain a better understanding of plant-endophytic bacterial interactions in the rhizosphere to create successful and reproducible biological controls in agriculture. The ecological interactions between plants and endophytic bacteria, however, are complex in the rhizosphere and are still far from being fully elucidated.

It is well established that chemotaxis toward root exudates (REs) is a key bacterial trait contributing to successful rhizosphere interactions (Raina et al. 2019) and biocontrol efficacy of inoculants under field conditions (Allardmassicotte et al. 2016; Ling et al. 2011; Tan et al. 2013; Ma et al. 2018). Numerous studies have shown the chemotactic response of endophytes to root exudates of host plants (Compant et al. 2010; Khare et al. 2018; Rosenblueth and Martínez-Romero 2006). Organic acids (OAs) are one of the key components in root exudates (Jones 1998; Liu and Wen 2006). Many studies have emphasized the regulatory role of OAs in plant-microbe interactions in the rhizosphere (el Zahar et al. 2014) and demonstrated that OAs can serve as major chemoattractants in root exudates that induce the recruitment of BCAs to the hosts, thus protecting roots from infection (Ling et al. 2011; Tan et al. 2013; Yuan et al. 2015; Zhang et al. 2013; Zhang et al. 2014). Therefore, chemotaxis toward OAs is putatively considered a bacterial trait that defines biocontrol ability against soil-borne pathogens.

At the molecular level, bacterial chemotaxis is mediated by a complex chemosensory pathway system composed of the sensor kinase CheA and response regulator CheY. Chemoreceptors, methyl-accepting proteins (MCPs), are transmembrane signal transducers located in the cytoplasmic membrane (Yang and Briegel 2020). CheA and CheY are the core proteins in the chemotaxis signaling pathway, and microbes possessing the encoding gene $c h e A$ are believed to be chemotactic (Bi et al. 2018). Accordingly, a molecular diagnostic tool based on the gene encoding the central regulator of bacterial chemotaxis (cheA) has been developed to characterise and track specific populations of native microbes in the rhizosphere with chemotactic potential (Buchan et al. 2010). The cheA-based approach is important because it allows researchers to easily distinguish chemotactic-competent bacteria in a population, which opens up new opportunities for the enrichment of functional species from plant-associated communities. Increasing evidence suggests that chemotaxis is a prevalent phenotype in the plant microbiome within the context of plant-microbe interactions (Li et al. 2012); however, to date, it remains unclear whether endophytic bacteria with chemotaxis potential are present in the microbiomes of medicinal plants.

Bacterial endophytes are important in soil-borne disease management, and chemotaxis improves rhizospheric interactions and the biocontrol efficacy of inoculants; it is very important to optimize the 
selection of endophytic sources with chemotactic potential to act as biocontrols against soil-borne disease and establish a basis for efficiently and practically applying antagonistic candidates in the field. Therefore, the objectives of the present study were as follows: (1) profile the abundance and diversity of the chemotactic-competent bacteria in an antagonistic endophytic bacteria (AEB) population of $P$. notoginseng with a cheA gene-based approach combined with 16S rRNA sequencing; (2) systematically evaluate the chemotaxis capabilities of chemotactic AEB (CAEB) populations in $P$. notoginseng using five OAs (citric, fumaric, malic, oxalic, and succinic acids) and characterise the diversity of chemotaxis profiles of the CAEB population to tested OAs, emphasizing the genus Bacillus; (3) investigate the effects of OAs on biocontrol-related traits of $P$. notoginseng-associated CAEB by targeting the main chemoattractant in tested OAs to evaluate its effect on chemotaxis and the growth and transcript levels of genes involved in the biocontrol activity of representative CAEB strains. This study could further the understanding of beneficial bacterial endophyte-plant interactions via chemotaxis toward OAs, facilitating the development of novel plant protection strategies.

\section{Materials And Methods}

Sample collection and isolation of endophytic bacteria

Root, stem, petiole, leaf and seed samples were collected from thirty 3 year old healthy $P$. notoginseng plants, grown in Luxi country of Yunnan Province, China. Surface disinfection of samples and isolation and purification of cultivable endophytic bacteria were performed according to the methods of $\mathrm{Ma}$ et al. (2013): Briefly, the samples were washed in running tap water to remove soil and the leaves, stems, petioles, and roots were separated and weighed individually, then immersed in $70 \%$ ethanol for 4 min, washed with fresh $2 \%$ sodium hypochlorite solution for 1-2 min, depending on the different tissues, followed by soaking in $70 \%$ ethanol for $1 \mathrm{~min}$ and finally washed three times with sterile distilled water. The disinfection process was checked by plating aliquots of the sterile distilled water used in the final rinse onto a plates containing KMB (King et al. 1954), NA ( $\mathrm{L}^{-1}$ : beef extract $3 \mathrm{~g}$, peptone $10 \mathrm{~g}, \mathrm{NaCl} 5 \mathrm{~g}$, agar $20 \mathrm{~g}$, distilled water $1,000 \mathrm{~mL}, \mathrm{pH} 7.0-7.2)$ and $\mathrm{YSP}$ media ( $\mathrm{L}^{-1}$ : peptone $10 \mathrm{~g}$, yeast extract $5 \mathrm{~g}$, glucose $20 \mathrm{~g}$, agar $20 \mathrm{~g}$, distilled water $1,000 \mathrm{~mL}, \mathrm{pH}$ 7.2) supplemented with $50 \mu \mathrm{g} \mathrm{mL}^{-1}$ of the fungicide Imazalil and incubating the plates at $32^{\circ} \mathrm{C}$ for 3 days. Sterile samples from the same tissue were homogenized in a sterilized mortar with $10 \mathrm{~mL}$ sterile distilled water under aseptic conditions. After filtration by passing through four layers of lens cleaning tissue (Whatman, Catalog Number: 2105 - 918), $200 \mu \mathrm{L}$ of appropriate dilutions was spread on a plates containing KMB, NA and YSP media. Triplicates were conducted for each medium of each sample. After incubation at $32^{\circ} \mathrm{C}$ for 3 days, bacterial colonies with unique morphotypes were picked and sub-cultured and the pure cultures thus obtained were used for the study.

Screening of AEB against pathogens of RRD in P. notoginseng

The fungal pathogen Fusarium oxysporum, the bacterial pathogen Ralstonia sp. and the parasitic nematode Meloidogyne hapla, which have been reported as three major pathogens associated with RRD 
of $P$. notoginseng (Miao et al. 2006), were used as the targets for antagonistic screening. The pathogens were isolated from root-rot samples of $P$. notoginseng. F. oxysporum and Ralstonia sp. were cultured respectively on potato dextrose agar (PDA) and NA media. Juveniles of $M$. hapla were obtained from rootrot samples by the Baermann-funnel method (Baermann 1917) and used directly. For antibacterial bioassay, $200 \mu \mathrm{L}$ fresh culture of Ralstonia sp. with concentration of $10^{8} \mathrm{CFU} \mathrm{mL}^{-1}$ was mixed with 250 $\mathrm{mL} \mathrm{NA}$ and evenly distributed into Petri dishes. On each plate, 6 wells of $5 \mathrm{~mm}$ diameter were made. Candidate bacteria were cultured in NB medium at $37^{\circ} \mathrm{C}, 200 \mathrm{rpm}$ for $48 \mathrm{~h}$ and the cell concentration was adjusted to $10^{7} \mathrm{CFU} \mathrm{mL}^{-1}$ with NB. $200 \mu \mathrm{L}$ of endophytic bacterial suspension was added to each well. An equivalent volume of liquid NB was used as control in place of bacterial culture. All treatments were tested in triplicate. After $48 \mathrm{~h}$ at $32^{\circ} \mathrm{C}$ diameters of antibacterial zones (AZ) were measured. Here, $\mathrm{AZ}$ was directly used to express the antibacterial efficiency of endophytic bacteria as the AZ value of the control was zero. Antifungal bioassays were performed following the Oxford cup method (Wang et al. 2009). An aliquot of $200 \mu \mathrm{L}$ culture candidate suspension, prepared as described above, was added into an Oxford cup (diameter $5 \mathrm{~mm}$ ) which was previously placed into the center of a PDA plate. Two $5 \mathrm{~mm}$ diameter of mycelial plugs of $F$. oxysporum from an actively growing colony were placed on two sides of the cup at a $2 \mathrm{~cm}$ distance. An equivalent volume of NB medium in place of the suspension was used as a control. All treatments were performed in triplicate. After incubation at $28^{\circ} \mathrm{C}$ for 4 days, antifungal efficiencies (AE) was calculated using the formula $A E=(D C-D T) / D C \times 100 \%$, where $D C$ and $D T$ respectively represented the colony diameters of $F$. oxysporum on the control and the treatments. For nematicidal bioassay in the wells of the 24-well microtitre plate, $200 \mu \mathrm{L}$ of bacterial culture prepared as above was mixed with $50 \mu \mathrm{L}$ of $M$. hapla suspension containing about 100 juveniles. Each treatment was replicated three times. Wells containing NB medium served as controls. After incubation at $28^{\circ} \mathrm{C}$ for $72 \mathrm{~h}$, the numbers of live and dead nematodes were counted under a stereomicroscope. The nematicidal efficiency (NE) was calculated using formula of $\mathrm{NE}=\mathrm{DN} / \mathrm{SN} \times 100 \%$, where $\mathrm{DN}$ represents the difference in number of dead nematodes between treatment and control, $\mathrm{SN}$ represents the sum of counted nematodes.

Screening of candidate chemotactic AEB (CAEB) via cheA gene detection

The bacterial DNA was extracted using a bacterial genomic DNA extraction kit (BioTeke Corporation, China, Cat\#: DP2001). The cheA gene was amplified by PCR using primers P4P5.for and P4P5.rev (Buchan et al. 2010). The $25 \mu \mathrm{L}$ reaction mixture consisted of $2 \mu \mathrm{L}$ DNA template, $3.75 \mathrm{U}$ Taq DNA polymerase (TaKaRa, Japan), $3 \mu \mathrm{L}$ 10×PCR reaction buffer supplied with the enzyme, $1.25 \mu \mathrm{L} 50 \mathrm{mM}$ $\mathrm{MgCl}_{2}, 1 \mu \mathrm{L}$ each $10 \mu \mathrm{M}$ primer, $13 \mu \mathrm{L} 2.5 \mathrm{mM}$ dNTP (Vivantis, Malaysia) and $3 \mu \mathrm{L}$ nuclease-free water (Promega, WI). The reaction conditions were $95^{\circ} \mathrm{C}$ for $3 \mathrm{~min}$, followed by 35 cycles of $95^{\circ} \mathrm{C}$ for $1 \mathrm{~min}$, $55^{\circ} \mathrm{C}$ for $1 \mathrm{~min}$ and $72^{\circ} \mathrm{C}$ for $2 \mathrm{~min}$, with a final extension step at $72^{\circ} \mathrm{C}$ for $3 \mathrm{~min}$. After purification using an Agarose gel DNA purification Kit (BioTeke Corporation, China, Cat\#: DP1502), the amplification products were detected by horizontal electrophoresis through 1\% SIGMA Type II agarose gels. The electrophoresis was performed at $120 \mathrm{~V}, 300 \mathrm{~mA}$, and the image was photographed under UV illumination using Gel Doc (BIO-RAD) software. Here, it must be pointed out that additional 64 AEB strains from $P$. 
notoginseng previously identified from our lab (Ma et al. 2013) also included this assay to screen chemotactic AEB.

Phylogenetic analysis of $P$. notoginseng-associated CAEB population

The 16S rRNA sequence-based phylogentic identification was done as previously described (Ma et al. 2013). The genomic DNA of bacteria was extracted using a bacterial (BioTeke Corporation, China, Cat\#: DP2001) and 16S rRNA genes were amplified by PCR using the primer pair of 27f and 1492r (Lane 1991). The PCR amplified products were separated by agarose gel electrophoresis, and sequenced on an $A B I$ Prism 3730 sequencer at Beijing Huada Biological Company. The identification of the closest phylogenetic neighbours and calculation of pairwise 16S rRNA gene sequence similarities were performed using the EzTaxon-e server http://www.ezbiocloud.net/ (Kim et al. 2012). Sequences chimera checking were performed by the program CHIMERA CHECK of the Ribosomal Database Project (RDP) (Maidak et al. 1997). Sequences with a potential chimeric structure were excluded from further analyses. The 16S rRNA gene sequences were aligned with representative bacterial using the Clustal W program in the MEGA 7 software package (Kumar et al. 2016). Phylogenetic analysis was done using the neighbourjoining method with kimura-2-parameter as a model of nucleotide substitution and complete deletion option as well as 1000 bootstrap replications in the MEGA 7 software package (Kumar et al. 2016). The partial 16S rDNA sequences of the representatives were deposited in GenBank (Table 1). 
Table 1

Information on the chemotactic antagonistic endophytic bacteria associated with root-rot disease of

Panax notoginseng including their closest phylogenetic affiliations, as well as their antagonistic pathogen targets and their isolated tissues

\begin{tabular}{|c|c|c|c|c|c|}
\hline Isolate ${ }^{a}$ & $\begin{array}{l}\text { Accession } \\
\text { number }\end{array}$ & $\begin{array}{l}\text { Closest NCBI library strain and } \\
\text { accession no. }\end{array}$ & $\begin{array}{l}\text { Similarity } \\
(\%)\end{array}$ & Pathogens ${ }^{b}$ & Origin \\
\hline L22 & JN700142 & $\begin{array}{l}\text { Acinetobacter calcoaceticus DSM } \\
30006^{\top}(\mathrm{X} 81661)\end{array}$ & 97.99 & Fo, Rs & Leaf \\
\hline NR1 & KP279972 & $\begin{array}{l}\text { Alcaligenes faecalis subsp. faecalis } \\
\text { IAM } 12369^{\top} \text { (D88008) }\end{array}$ & 99.35 & $\mathrm{Mh}$ & Root \\
\hline NP2 & KP279970 & $\begin{array}{l}\text { Alcaligenes faecalis subsp. faecalis } \\
\text { IAM } 12369^{\top}(\text { D } 88008)\end{array}$ & 99.35 & Mh,Rs & Petiole \\
\hline KL1 & KP279955 & Bacillus aerophilus $28 \mathrm{~K}^{\top}$ (AJ831844) & 99.92 & $\mathrm{Mh}$ & Leaf \\
\hline KR2 & KP279960 & Bacillus aerophilus 28K' (AJ831844) & 99.93 & Mh,Fo & Root \\
\hline NL2 & KP279967 & Bacillus aerophilus $28 \mathrm{~K}^{\top}$ (AJ831844) & 99.93 & Fo & Leaf \\
\hline YL1 & KP279983 & $\begin{array}{l}\text { Bacillus amyloliquefaciens subsp. } \\
\text { plantarum } \text { FZB42 }^{\top}(\mathrm{CP} 000560)\end{array}$ & 99.93 & Fo, Rs & Leaf \\
\hline YP1 & KP279984 & $\begin{array}{l}\text { Bacillus amyloliquefaciens subsp. } \\
\text { plantarum FZB42 }{ }^{\top}(\mathrm{CP} 000560)\end{array}$ & 99.85 & Mh,Fo, Rs & Petiole \\
\hline YR3 & KP279987 & $\begin{array}{l}\text { Bacillus amyloliquefaciens subsp. } \\
\text { plantarum } \text { FZB42 }^{\top} \text { (CP000560) }\end{array}$ & 99.85 & $\mathrm{Mh}$ & Root \\
\hline L9 & JN700139 & $\begin{array}{l}\text { Bacillus amyloliquefaciens subsp. } \\
\text { plantarum } \text { FZB42 }^{\top} \text { (CP000560) }\end{array}$ & 99.52 & Rs & Leaf \\
\hline St08 & JN700078 & $\begin{array}{l}\text { Bacillus amyloliquefaciens subsp. } \\
\text { plantarum } \mathrm{FZB}{ }^{\top}{ }^{\top} \text { (CP000560) }\end{array}$ & 99.45 & Mh & Stem \\
\hline R12 & JN700082 & 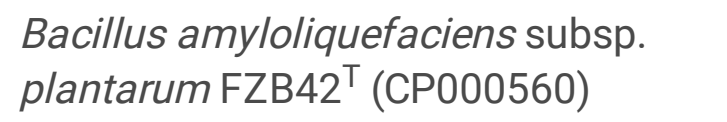 & 99.65 & Fo, Mh, Rs & Root \\
\hline R7 & JN700090 & $\begin{array}{l}\text { Bacillus amyloliquefaciens subsp. } \\
\text { plantarum } \mathrm{FZB} 42^{\top}(\mathrm{CP} 000560)\end{array}$ & 99.93 & Fo, Rs & Root \\
\hline L14 & JN700122 & $\begin{array}{l}\text { Bacillus aryabhattai B8W22 }{ }^{\top} \\
(\mathrm{EF} 114313)\end{array}$ & 98.77 & Mh & Leaf \\
\hline L13 & JN700141 & $\begin{array}{l}\text { Bacillus aryabhattai B8W22 }{ }^{\top} \\
\text { (EF114313) }\end{array}$ & 98.37 & Mh & Leaf \\
\hline KL2 & KP279956 & $\begin{array}{l}\text { Bacillus cereus ATCC } 14579^{\top} \\
\text { (AE016877) }\end{array}$ & 100 & Fo, Mh, Rs & Leaf \\
\hline
\end{tabular}




\begin{tabular}{|c|c|c|c|c|c|}
\hline Isolate ${ }^{a}$ & $\begin{array}{l}\text { Accession } \\
\text { number }\end{array}$ & $\begin{array}{l}\text { Closest NCBI library strain and } \\
\text { accession no. }\end{array}$ & $\begin{array}{l}\text { Similarity } \\
(\%)\end{array}$ & Pathogens ${ }^{b}$ & Origin \\
\hline St05 & JN700065 & $\begin{array}{l}\text { Bacillus methylotrophicus } \mathrm{CBMB}^{2} \mathrm{~S}^{\top} \\
\text { (EU194897) }\end{array}$ & 100 & Mh,Fo & Stem \\
\hline R18 & JN700091 & $\begin{array}{l}\text { Bacillus methylotrophicus }{\text { CBMB } 205^{\top}}^{\top} \\
\text { (EU194897) }\end{array}$ & 99.23 & $\mathrm{Mh}$ & Root \\
\hline YR7 & KP279991 & $\begin{array}{l}\text { Bacillus mycoides DSM } 2048^{\top} \\
\text { (ACMU01000002) }\end{array}$ & 99.56 & Fo & Root \\
\hline KL3 & KP279957 & $\begin{array}{l}\text { Bacillus safensis FO- } \\
036 b^{\top}(\mathrm{AF} 234854)\end{array}$ & 100 & Fo,Rs & Leaf \\
\hline KP1 & KP279958 & $\begin{array}{l}\text { Bacillus safensis } \mathrm{FO}-036 \mathrm{~b}^{\top} \\
\text { (AF234854) }\end{array}$ & 100 & Fo & Petiole \\
\hline KR3 & KP279961 & $\begin{array}{l}\text { Bacillus safensis FO- } 036 b^{\top} \\
\text { (AF234854) }\end{array}$ & 100 & Rs & Root \\
\hline NS3 & KP279980 & $\begin{array}{l}\text { Bacillus safensis } \mathrm{FO}-036 \mathrm{~b}^{\top} \\
\text { (AF234854) }\end{array}$ & 98.76 & Mh, Rs & Stem \\
\hline YR1 & KP279985 & $\begin{array}{l}\text { Bacillus safensis } \mathrm{FO}-036 \mathrm{~b}^{\top} \\
\text { (AF234854) }\end{array}$ & 100 & Mh & Root \\
\hline YR2 & KP279986 & $\begin{array}{l}\text { Bacillus safensis } \mathrm{FO}-036 \mathrm{~b}^{\top} \\
\text { (AF234854) }\end{array}$ & 99.93 & Fo, Mh, Rs & Root \\
\hline YS2 & KP279994 & $\begin{array}{l}\text { Bacillus safensis FO- } \\
036 b^{\top}(\mathrm{AF} 234854)\end{array}$ & 100 & Rs & Stem \\
\hline NL3 & KP279968 & $\begin{array}{l}\text { Bacillus safensis FO- } \\
036 b^{\top}(\mathrm{AF} 234854)\end{array}$ & 99.93 & Mh,Fo & Leaf \\
\hline NR6 & KP279977 & $\begin{array}{l}\text { Bacillus simplex NBRC } 15720^{\top} \\
(\text { AB363738) }\end{array}$ & 99.93 & Fo, Mh & Root \\
\hline KR5 & KP279963 & Bacillus tequilensis $10 \mathrm{~b}^{\top}(\mathrm{HQ} 223107)$ & 99.85 & Fo, Rs & Root \\
\hline YR5 & KP279989 & Bacillus tequilensis $10 \mathrm{~b}^{\top}(\mathrm{HQ} 223107)$ & 99.93 & Fo & Root \\
\hline KS2 & KP279965 & $\begin{array}{l}\text { Bacillus xiamenensis } \mathrm{HYC}^{-10^{\top}} \\
\text { (AMSH01000114) }\end{array}$ & 100 & Mh, Rs & Stem \\
\hline YR4 & KP279988 & $\begin{array}{l}\text { Brevibacillus borstelensis NRRL NRS- } \\
818^{\top} \text { (D78456) }\end{array}$ & 99.93 & $\mathrm{Mh}$ & Root \\
\hline YR8 & KP279992 & $\begin{array}{l}\text { Brevibacillus borstelensis NRRL NRS- } \\
818^{\top}(\mathrm{D} 78456)\end{array}$ & 99.93 & Fo, Rs & Root \\
\hline
\end{tabular}




\begin{tabular}{|c|c|c|c|c|c|}
\hline Isolate ${ }^{a}$ & $\begin{array}{l}\text { Accession } \\
\text { number }\end{array}$ & $\begin{array}{l}\text { Closest NCBI library strain and } \\
\text { accession no. }\end{array}$ & $\begin{array}{l}\text { Similarity } \\
(\%)\end{array}$ & Pathogens ${ }^{b}$ & Origin \\
\hline NS4 & KP279981 & $\begin{array}{l}\text { Enhydrobacter aerosaccus LMG } \\
21877^{\top} \text { (AJ550856) }\end{array}$ & 98.12 & $\mathrm{Mh}$ & Stem \\
\hline L25 & JN700133 & $\begin{array}{l}\text { Enterobacter ludwigii DSM } 16688^{\top} \\
\text { (AJ853891) }\end{array}$ & 99.38 & Mh, Fo & Leaf \\
\hline YS3 & KP279995 & $\begin{array}{l}\text { Kytococcus sedentarius DSM } \\
20547^{\top} \text { (CP001686) }\end{array}$ & 99.85 & Rs & Stem \\
\hline P17 & JN700149 & $\begin{array}{l}\text { Lysinibacillus sphaericus ATCC } \\
14577^{\top}(\text { L14010) }\end{array}$ & 97.85 & $\mathrm{Mh}$ & Petiole \\
\hline P15 & JN700164 & $\begin{array}{l}\text { Lysinibacillus sphaericus ATCC } \\
14577^{\top} \text { (L14010) }\end{array}$ & 97.94 & $\mathrm{Mh}$ & Petiole \\
\hline
\end{tabular}


Table 1

Continued.

\begin{tabular}{|c|c|c|c|c|c|}
\hline Isolate $^{a}$ & $\begin{array}{l}\text { Accession } \\
\text { number }\end{array}$ & $\begin{array}{l}\text { Closest NCBI library strain and } \\
\text { accession no. }\end{array}$ & $\begin{array}{l}\text { Similarity } \\
(\%)\end{array}$ & Pathogens ${ }^{b}$ & Origin \\
\hline NP1 & KP279969 & $\begin{array}{l}\text { Micrococcus yunnanensis YIM } \\
65004^{\top} \text { ( FJ214355) }\end{array}$ & 99.78 & Fo & Petiole \\
\hline NR5 & KP279976 & $\begin{array}{l}\text { Paenibacillus taiwanensis BCRC } \\
17411^{\top}(\mathrm{DQ} 890521)\end{array}$ & 99.36 & Fo, Rs & Root \\
\hline NL1 & KP279966 & $\begin{array}{l}\text { Pantoea brenneri LMG } 5343^{\top} \\
\text { (EU216735) }\end{array}$ & 99.7 & Rs & Leaf \\
\hline KS1 & KP279964 & $\begin{array}{l}\text { Pantoea vagans } \mathrm{LMG} 24199^{\top} \\
(\mathrm{EF} 688012)\end{array}$ & 99.71 & Fo & Stem \\
\hline NS1 & KP279978 & $\begin{array}{l}\text { Pantoea vagansLMG } 24199^{\top} \\
\text { (EF688012) }\end{array}$ & 99.72 & $\mathrm{Mh}$ & Stem \\
\hline KR4 & KP279962 & $\begin{array}{l}\text { Pseudomonas chlororaphis subsp. } \\
\text { aurantiaca NCIB } 10068^{\top} \text { (DQ682655) }\end{array}$ & 99.93 & $\mathrm{Mh}$ & Root \\
\hline NR4 & KP279975 & $\begin{array}{l}\text { Pseudomonas chlororaphis subsp. } \\
\text { aurantiaca NCIB } 10068^{\top} \text { (DQ682655) }\end{array}$ & 99.93 & Mh, Rs & Root \\
\hline YR6 & KP279990 & $\begin{array}{l}\text { Pseudomonas chlororaphis subsp. } \\
\text { aurantiaca NCIB } 10068^{\top} \text { (DQ682655) }\end{array}$ & 99.93 & Fo & Root \\
\hline NR3 & KP279974 & $\begin{array}{l}\text { Pseudomonas chlororaphis subsp. } \\
\text { aurantiaca NCIB } 10068^{\top} \text { (DQ682655) }\end{array}$ & 99.78 & Rs & Root \\
\hline NR2 & KP279973 & $\begin{array}{l}\text { Pseudomonas helmanticensis } \\
\mathrm{OHA}_{11}{ }^{\top}(\mathrm{HG} 940537)\end{array}$ & 99.48 & Mh, Fo & Root \\
\hline YS1 & KP279993 & $\begin{array}{l}\text { Pseudomonas helmanticensis } \\
\mathrm{OHA}_{1} 1^{\top}(\mathrm{HG} 940537)\end{array}$ & 99.64 & $\mathrm{Mh}$ & Stem \\
\hline KR1 & KP279959 & $\begin{array}{l}\text { Pseudomonas moraviensis CCM } \\
7280^{\top} \text { (AY970952) }\end{array}$ & 99.41 & Rs & Root \\
\hline L21 & JN700130 & 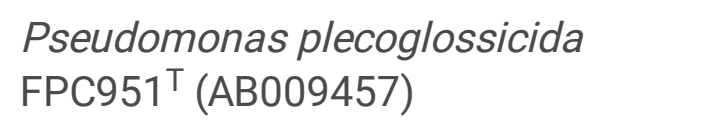 & 98.82 & $\mathrm{Mh}$ & Leaf \\
\hline NP3 & KP279971 & $\begin{array}{l}\text { Sphingomonas dokdonensis DS- } \\
4^{\top}(\mathrm{DQ} 178975)\end{array}$ & 99.18 & FO & Petiole \\
\hline
\end{tabular}

a The chemotactic antagonistic endophytic bacteria of $P$. notoginseng, the present study obtained, were encoded such as KL1, NS1, YR1, YS1 et al according to combination of the initial of the abbreviation of isolation media, the tissues and the numbers indicating. ${ }^{\mathrm{b}}$ Fo, Fusarium oxysporum, Rs, Ralstonia sp., Mh, Meloidogyne hapla. 


\begin{tabular}{|c|c|c|c|c|c|}
\hline Isolate $^{a}$ & $\begin{array}{l}\text { Accession } \\
\text { number }\end{array}$ & $\begin{array}{l}\text { Closest NCBI library strain and } \\
\text { accession no. }\end{array}$ & $\begin{array}{l}\text { Similarity } \\
(\%)\end{array}$ & Pathogens ${ }^{b}$ & Origin \\
\hline NS2 & KP279979 & $\begin{array}{l}\text { Staphylococcus arlettae ATCC } \\
43957^{\top}(\text { AB009933) }\end{array}$ & 100 & Rs & Stem \\
\hline NS5 & KP279982 & $\begin{array}{l}\text { Staphylococcus hominis subsp. } \\
\text { hominis DSM } 20328^{\top}(\mathrm{X} 66101)\end{array}$ & 99.86 & Fo,Rs & Stem \\
\hline L18 & JN700131 & $\begin{array}{l}\text { Stenotrophomonas rhizophila e-p10 } 10^{\top} \\
\text { (AJ293463) }\end{array}$ & 98.62 & Fo, Rs & Leaf \\
\hline L19 & JN700143 & $\begin{array}{l}\text { Stenotrophomonas rhizophila e-p10 } \\
\text { (AJ293463) }\end{array}$ & 98.27 & $\mathrm{Mh}$ & Leaf \\
\hline \multicolumn{6}{|c|}{$\begin{array}{l}\text { a The chemotactic antagonistic endophytic bacteria of } P \text {. notoginseng, the present study obtained, } \\
\text { were encoded such as KL1, NS1, YR1, YS1 et al according to combination of the initial of the } \\
\text { abbreviation of isolation media, the tissues and the numbers indicating. }{ }^{b} \text { Fo, Fusarium oxysporum, } \\
\text { Rs, Ralstonia sp., Mh, Meloidogyne hapla. }\end{array}$} \\
\hline
\end{tabular}

Chemotaxis experiments

Qualitative soft agar drop plate assays

Bacterial chemotaxis was tested using a soft-agar drop plate assay as described previously (Li et al. 2012; Samanta et al. 2000) with slight modification. Briefly, bacteria were grown in NB medium at $32^{\circ} \mathrm{C}$, $180 \mathrm{rpm}$. At log phase $\left(\mathrm{OD}_{600}=0.3\right)$, bacterial cells were harvested and washed three times with chemotactic buffer (MM solution: $10 \mathrm{mM}$ potassium phosphate buffer ( $\mathrm{pH}$ 7.0), $0.1 \mathrm{mM}$ EDTA, $0.05 \%$

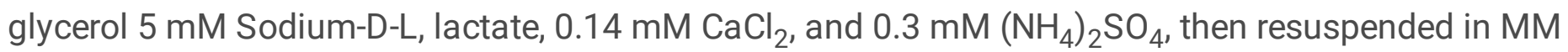
solution at $\sim 1 \times 10^{8} \mathrm{CFU} \mathrm{mL}^{-1}$, and $5 \mathrm{~mL}$ of cell suspension was added into a Petri dish containing drop assay medium (MM solution containing $0.3 \%$ agar and $1 \mathrm{mM}$ glucose as an energy source); the same volume of chemotactic buffer was used as a negative control. Then $0.1 \mathrm{~g}$ of each organic acid compound (citric acid, fumaric acid, malic acid, oxalic acid, and succinic acid) in crystal form was placed in the center of each plate, and an equivalent weight of aspartic acid served as the positive control. No substrate negative controls were used. After incubation for over $12 \mathrm{~h}$ at room temperature $\left(25^{\circ} \mathrm{C}\right)$, the chemotactic response was observed as the formation of a chemotactic ring near the center of each Petri dish and scored on a scale as described previously (Greer-Phillips et al. 2003; Repik et al. 2000).

Subsequently, based on the diameter of the chemotactic ring and bacterial phylogenetic affiliation, hierarchical clustering was performed to characterise chemotactic response profiles toward the five organic acids across the representative $\mathrm{CAEB}$ associated with $P$. notoginseng using the cluster $\mathrm{R}$ package (Maechler et al. 2017). The heatmap was realized with the Pheatmap R package (Kolde R. Pheatmap: Pretty Heatmaps; R package version 1.0.8).

Quantitative capillary assays 
Capillary assays were performed according to the previously described protocol for quantitatively measuring the chemotaxis response of the bacteria to the chemoattractants (Adler 1973; Rudrappa et al. 2008). The bacterial strain was grown in culture liquid media until the $\mathrm{OD}_{600}$ reached $0.4-0.6$, at which point the cells were collected by centrifugation and washed twice with chemotactic buffer, then adjusted to an $\mathrm{OD}_{600}$ of 0.1 for further testing. $A 60-\mathrm{mm}$ Petri dish was loaded with $10 \mathrm{~mL}$ of the cell suspension prepared above. A standard $1 \mu \mathrm{L}$ capillary was filled with the $\mathrm{OAs}$ at different concentrations $(0,10,25$, 50 , and $100 \mu \mathrm{M}$ ) and immersed in the cell suspension in the Petri dishes. After $2 \mathrm{~h}$ incubation at room temperature, capillary contents were serially diluted in sterile phosphate buffer and plated on LB plates. The number of bacteria accumulating in the capillaries was determined by CFU counting in LB plates incubated for $48 \mathrm{~h}$. Phosphate buffer served as a control. Each treatment was replicated three times. Responses to the attractants were expressed as the relative chemotactic response (RCR), representing the ratio of the cells accumulated in capillaries containing attractants and phosphate buffer (control). An RCR value of 1 and 2 or greater indicates no chemotaxis and significant chemotaxis, respectively.

Effects of OAs on the growth of the representative $P$. notoginseng-associated CAEB strain in vitro An assay was designed to evaluate the effect of exogenous OAs at different concentrations on the growth of representative CAEB as previously described (Liu et al. 2019). The bacterial cells were incubated overnight in $10 \mathrm{~mL}$ NB medium and then adjusted to an $\mathrm{OD}_{600}$ of 0.1 . Subsequently, a $1 \mathrm{~mL}$ aliquot of the resulting suspension was inoculated into $100 \mathrm{~mL}$ of minimal medium (MM) with different concentrations of an $\mathrm{OA}$ as the sole carbon source. Cultures were incubated at $32^{\circ} \mathrm{C}$ with $180 \mathrm{rpm}$ shaking for $48 \mathrm{~h}$, and finally, the $\mathrm{OD}_{600}$ was monitored from each treatment. Each treatment group composed of three replicates, and sterile deionized water was used instead of OAs as a control.

Transcription analysis of chemotaxis and biocontrol-related genes in representative $P$. notoginsengassociated CAEB strains in the presence of an OA

To determine the influence of OAs on the transcript levels of biocontrol-related genes in the $P$. notoginseng-associated CAEB strain, the following modified experiment was performed: (1) strain grown in NB medium without individual OAs (control); (2) strain grown in NB medium containing individual OAs at an appropriate concentration. Strain cultures were incubated overnight and then adjusted to an $\mathrm{OD}_{600}$ of 0.1 . A $1 \mathrm{~mL}$ aliquot of culture was then transferred to NB medium containing an $\mathrm{OA}$ at an appropriate concentration and incubated at $37^{\circ} \mathrm{C}$ with $180 \mathrm{rpm}$ shaking for $28 \mathrm{~h}$. Cells were harvested and then total RNA was extracted using an E.Z.N.A. Bacterial RNA Kit (OMEGA, USA) according to the manufacture's protocol. RNA quantity and quality were analysed by micro-spectrophotometry (NanoDrop Technologies Inc.). Next, $20 \mu \mathrm{L}$ samples were used to synthesize cDNA using a reverse transcription system (Transgen, Beijing, China). Quantitative expression analysis of the chemotaxis-related gene cheA and selected biocontrol-related genes ( $s r f A A, b m y B$, bioA, yndJ, srfAB, Ipa-14, sft) were carried out with SYBR Premix EX Taq (Takara, Dalian, China) using a thermal cycler Biorad CFX96 Real-Time PCR System (Applied Biosystems, USA), based on the manufacturer's instructions. The relative gene expression level was calculated with the $2^{-\triangle \Delta C T}$ method (Livak and Schmittgen 2001). The $16 S$ rRNA gene was employed as 
the internal control for gene expression analysis. Fold induction was calculated by comparing gene expression for growth in the presence of an OA to growth in the absence of an OA. Three replicates were conducted for each treatment. These genes were selected for transcription analysis based on previous studies that found evidence suggesting that those genes are important for the biocontrol efficacy of bacteria (Bais et al. 2004; Joshi and Gardener 2006; Ongena and Jacques 2008). These included lipid peptide antibiotic synthesis genes ( $\operatorname{sf} A A, b m y B)$, a biotin synthase gene (bioA), an antibacterial protein synthesis gene ( $y n d J)$, the lipid peptide antibiotic family (Ipa-14, sifAB), and a surfactin production gene $(s f t)$ in the Bacillus sp. The primers of the target genes were used according to previous studies (Wu et al. 2015; Wu et al. 2017).

\section{Statistical analysis}

Differences among treatments were analysed using an ANOVA followed by Fisher's LSD test. Before analysis, data were log-transformed to reach normality. The Kolmogorov-Smirnov test was applied to test for a normal distribution ( $p>0.05$ ). Additionally, differences between the presence and absence of nicotine treatments were analysed by the independent-samples t-test at the $5 \%$ level. All statistical analyses were performed with the SPSS BASE ver.17.0 statistical software (SPSS, Inc., Chicago, USA). Rejection level was set at $p<0.05$ for all analyses. Unless stated otherwise, all values reported are means \pm standard deviation (SD).

\section{Results}

Candidate chemotactic AEB for RRD from $P$. notoginseng

We previously reported that 104 endophytic strains of $P$. notoginseng screened from leaf, petiole, stem, root, and seed samples grown in Wenshan region of Yunnan Province, China exhibited antagonistic properties against at least one RRD pathogen (Fusarium oxysporum, Ralstonia sp., and Meloidogyne hapla) (Ma et al. 2013), but previous studies have indicated that the abundance, diversity, and species assemblage of endophytes can be strongly influenced by the geographic regions they occur in (Deng et al. 2011; Yaish et al. 2015). These observations prompted us to further study the antagonistic endophytes associated with $P$. notoginseng growing in a different geographic area (Luxi County, Yunnan Province, China) to explore novel and more extensive antagonistic endophytes associated with RRD of $P$. notoginseng. Accordingly, 600 endophytic bacteria were isolated from different tissues (leaf, petiole, stem, and root) of $P$. notoginseng grown in Luxi County, different ecological region from Wenshan County in Yunnan Province, China, and were further evaluated in vitro for their antagonistic activity towards the pathogens F. oxysporum, Ralstonia sp., and M. hapla. Of the 600 isolates, 118 strains showed antagonistic activity against at least one of the tested pathogens (Table 1). PCR amplification using the P4P5.for and P4P5.rev primer pair revealed that 56 of the 222 isolates (104 previously isolated and 118 obtained from the present study) produced a characteristic cheA band (approximately $500 \mathrm{bp}$ ), which could be taken as chemotactic candidates (Table 1). The chemotactic ability of all 56 candidates that produced the $c h e A$ band was verified by the drop assay with aspartic acid, which was used as the 
attractant in a previously described chemotaxis assay (Singh et al. 2010). Results indicated that the 56 candidates could be taken as chemotactic strains because they all exhibited positive chemotaxis toward the tested aspartic acid (Fig. S1 and Table S1).

Phylogeny of $P$. notoginseng-associated chemotactic AEB

The 16S rRNA gene phylogenetic analysis was used to assign all 56 chemotactic AEB (CAEB) into three bacterial groups: Actinobacteria, Firmicutes, and Proteobacteria (Fig. 1 and Table 1). The most abundant class of CAEB was the Actinobacteria group, which contained 35 strains ( $62.5 \%$ of the total). In this group, Bacillus spp. represented the most dominant genus with 28 isolates $(80.0 \%$ of the Actinobacteria group), and the majority of the Bacillus isolates were associated with the species of $B$. safensis (8 strains) and B. amyloliquefaciens subsp. plantarum (7), with similarities of $98.76-100 \%$ and $99.45-$ $99.93 \%$, respectively, whereas all other 13 Bacillus spp. isolates belonged to eight species with similarities of $98.37-100 \%$ : B. aerophilus (3 isolates), B. aryabhattai (2), B. methylotrophicus (2), B. tequilensis (2), $B$. cereus (1), B. mycoides (1), B. simplex (1), and B. xiamenensis (1). The seven remaining members of Actinobacteria were affiliated with five species from four genera with similarities of $97.85-100 \%$ : Staphylococcus hominis subsp. hominis (1), Staphylococcus arlettae (1), Lysinibacillus sphaericus (2), Paenibacillus taiwanensis (1), and Brevibacillus borstelensis (2). The 19 strains related to Proteobacteria made up the second-largest fraction (33.9\% of the total) of the CAEB communities, and included alpha, beta, and gamma subdivisions with similarities of $97.99-99.93 \%$. Of the 19 strains affiliated with Proteobacteria, the majority (16) exhibited high similarity to Gammaproteobacteria. However, only three strains were grouped into alpha and beta subdivisions of Proteobacteria, with 99.18-99.35\% sequence similarity to Sphingomonas dokdonensis and Alcaligenes faecalis subsp. faecalis. Additionally, the 16 strains in the class Gammaproteobacteria consisted of six genera: Pseudomonas, Acinetobacter, Enterobacter, Enhydrobacter, Pantoea, Stenotrophomonas. Of the Gammaproteobacteria strains, most were related to four species in the genus Pseudomonas: P. chlororaphis subsp. aurantiaca (4), $P$. helmanticensis (2), P. moraviensis (1), P. plecoglossicida (1). Finally, two isolates were grouped into Actinobacteria, and they accounted for $3.6 \%$ of the total. Among them, one was found to belong to the family Micrococcaceae, showing $99.78 \%$ similarity with Micrococcus yunnanensis, and the other was most closely related to the lineage of Dermacoccacea in Actinobacteria, with $99.85 \%$ sequence similarity to Kytococcus sedentarius.

Chemotaxis toward organic acids by $P$. notoginseng-associated CAEB

The chemotactic response toward the five organic acids (OAs; citric acid (CA), fumaric acid (FA), malic acid (MA), oxalic acid (OX), succinic acid (SA)) for CAEB from $P$. notoginseng was determined in drop medium plates containing $0.1 \mathrm{~g}$ of crystallized $O A$ as a chemosubstrate at the center of each plate. The presence of one of more concentric rings radiating away from the tested compound was considered positive for chemotaxis. The strength of the bacterial chemotactic response was quantified by measuring the diameter of the chemotactic ring. The substrates tested and chemotactic responses of the representative 32 strains observed are listed in Fig. S1-6 and Table S1 to illustrate the scoring of the 
chemotactic response. Chemotactic ring diameters were used to measure response: $>51 \mathrm{~mm}=$ strongest response, $31-50 \mathrm{~mm}$ = stronger response, $21-30 \mathrm{~mm}=$ strong response, and 1-20 $\mathrm{mm}=$ weaker response. A stronger response indicated that more cells accumulated near the attractants, and that they formed a dense ring. Overall, FA-followed by CA and MA-invoked the strongest positive chemotaxis in tested strains according the chemotactic response scoring (diameter of the chemotactic ring) (Fig. 2). As shown in Fig. 2, Fig. S3, and Table S1, all 32 tested strains showed chemotactic rings with diameters $>31$ $\mathrm{mm}$ when FA was used as the chemoattractant. Additionally, the majority of the strains $(23,71.9 \%$ of the tested strains) displayed the strongest chemotactic response to CA (51-77 mm diameter) and three strains exhibited a stronger response $(33-46 \mathrm{~mm})$. Fifteen strains displayed the strongest chemotactic response to MA (54-70 mm) and eight strains exhibited a strong response (35.8-50.7 mm). In contrast, SA and OA elicited relatively lower positive chemotaxis in about half of the tested strains. For example, 12 strains exhibited the weaker positive chemotactic response to OA (diameter $<15 \mathrm{~mm}$ ), and nine strains displayed the weaker chemotactic response to SA (diameter < $18 \mathrm{~mm}$ ). Interestingly, among all the tested strains, four (KL1, YP1, KR4, and YR3) exhibited a stronger chemotactic response towards all tested OAs, as evident by the diameter of the chemotactic ring being $>40 \mathrm{~mm}$ (Fig. S2-6 and Table S1), which indicated that these strains could be candidates for further study.

\section{Diverse chemotactic response profiles across $P$. notoginseng-associated CAEB}

At the genus level, chemotactic response profiles of the CAEB strains varied greatly across all of the tested OAs, and there was no general trend in strong or weak chemotaxis for any of the phylogenetic relationships. Using hierarchical cluster analysis and a heatmap, CAEB strains belonging to different genera (12 genera) exhibited different chemotactic responses to the same tested OAs, even when the strains were responding to a positive control AS (Fig. 3). For example, strain L22 (affiliated with Acinetobacter calcoaceticus) exhibited the strongest chemotactic response to CA, as evident by the diameter of the chemotactic ring reaching $70 \mathrm{~mm}$ (Table S1 and Fig. S2). However, very weak chemotaxis of strain YS3 (Kytococcus sedentarius) was measured in the diameter of the chemotactic ring responding to CA (5 mm; Table S1, Fig. S2). Similarly, strain KS1-classified as Pantoea vagans-showed the strongest chemotactic response to MA, with a diameter of $70 \mathrm{~mm}$ (Table S1, Fig. S4). In contrast, strain NP3 (affiliated with Sphingomonas dokdonensis) exhibited very weak chemotaxis to MA (5 mm diameter; Table S1 and Fig. S4). There was no chemotaxis toward SA in the case of strain NP3 (affiliated with S. dokdonensis), whereas NR2 (Pseudomonas helmanticensis) displayed the strongest chemotactic response to SA, with a chemotactic ring $74.2 \mathrm{~mm}$ in diameter (Table S1 and Fig. S6).

Additionally, within the same genus, different species have diverse chemotactic response profiles, as demonstrated by Bacillus (Fig. S7 and Table S2). We found considerable diversity in chemotactic response profiles among the 15 strains of Bacillus using hierarchical cluster analysis and a heatmap (Fig. 4). Two strains-L14 and NL2, classified as B. aryabhattai and B. aerophilus, respectively-showed the strongest chemotactic response to CA, while another strain-R7, classified as $B$. amyloliquefaciens subsp. plantarum-exhibited very weak chemotaxis to CA. In the case of MA, three strains (L9, YR5, and KR2, affiliated with $B$. amyloliquefaciens subsp. plantarum, B. tequilensis, and $B$. aerophilus, respectively) 
displayed a weaker response (chemotactic ring diameter of 2.0,2.0, and $5.0 \mathrm{~mm}$, respectively). In contrast, three other strains (YR7, YP1, and R18, classified as B. mycoides, B. amyloliquefaciens subsp. plantarum, and $B$. methylotrophicus, respectively) exhibited the strongest chemotactic response, with a chemotactic ring $>60 \mathrm{~mm}$ in diameter. In response to the SA, the 15 strains of Bacillus displayed a range of chemotaxis profiles, from 0 to $69.6 \mathrm{~mm}$ in diameter; e.g., strain L14 (affiliated with $B$. aryabhattai) was nonchemotactic to SA, but strain YR5 (classified as $B$. tequilensis) showed the strongest chemotactic response towards SA. Interestingly, in our study, the chemotactic response towards specific chemoattractants was found to be diverse not only among species but also among strains of a single species. For example, we found a striking diversity in the responses to all tested substrates across all five strains of $B$. amyloliquefaciens subsp. plantarum, as all the strains displayed unique chemotaxis response profiles to tested substrates (Fig. 4 and Fig. S7 and Table S2).

Assessment in the chemotaxis of the representative $P$. notoginseng-associated CAEB strain $B$. amyloliquefaciens subsp. plantarum YP1 in the presence of OAs

Taking the antagonism, chemotactic response profiles, strength of chemotaxis, and affiliation to the genus Bacillus into consideration, B. amyloliquefaciens subsp. plantarum YP1 was selected as the representative strain to evaluate the role of OAs-identified previously in root exudates of $P$. notoginseng (Li et al. 2015), in the biocontrol traits of the $P$. notoginseng-associated CAEB assemblage-concerning chemotaxis, growth, and antagonistic activity. A modified capillary assay was performed to assess the effects of OAs on the chemotaxis of YP1. The results showed that all tested OAs at concentrations of 10 to $100 \mu \mathrm{M}$ significantly induced chemotactic activity in YP1 (Fig. 5). The concentrations of OAs (10 to $100 \mu \mathrm{m}$ ) tested in quantitative chemotaxis studies were chosen, as several studies have shown that OAs detected in REs at this concentration range lead to positive and apparent chemotaxis responses in Bacillus, and thus this range is commonly employed in capillary assays (Ling et al. 2011; Tan et al. 2013). The effects of OAs on the chemotactic response of YP1 differed depending on the OAs used. In general, CA and FA stimulated chemotaxis in YP1 markedly more than other OA treatments. FA had particularly marked effects on YP1 chemotaxis at various tested concentrations, and the RCR values obtained at concentrations from 10 to $100 \mu \mathrm{M}$ were 1.1- to 1.3-fold higher in the FA treatment (Fig. 5A) than the CA one (Fig. 5B). Meanwhile, additional comparative analyses showed that FA and CA induced the chemotaxis of YP1 in a concentration-dependent manner within a dose range of 10 to $50 \mu \mathrm{M}$, and a 50 $\mu \mathrm{M}$ concentration yielded the highest chemotaxis in both cases $(R C R=6.73$ for $F A$ and $R C R=5.20$ for $C A$, Fig. $5 A$ and $B$, respectively). The quantitative reverse transcription-PCR (qRT-PCR) regarding che $A$ relative gene expression levels in YP1 demonstrated that FA at $50 \mu \mathrm{M}$ induced the highest increase in cheA gene transcript expression (Fig. 6).

Effects of FA on the growth of B. amyloliquefaciens subsp. plantarum YP1 in vitro

The results of the capillary assay suggested that the most potent chemoattractant among tested OAs for strain YP1 was FA, as evident by the observation that FA invoked the highest chemotaxis in YP1, especially at a concentration of $50 \mu \mathrm{M}(\mathrm{RCR}=6.73)($ Fig. $6 \mathrm{~A})$. Therefore, we putatively selected FA as the 
target to evaluate the effects of OAs on the growth and biocontrol activity of $P$. notoginseng-associated CAEB. Compared to the control $(0 \mu \mathrm{M})$, exogenous applications of different concentrations of FA had different but stimulating effects on YP1 growth at concentrations of 25 to $100 \mu \mathrm{M}$ (Fig. 7). Early in incubation (12 h), YP1 had a similar growth tendency in the presence of FA and CK. Subsequently, the results showed that FA significantly stimulated the growth of YP1 at 25 and $50 \mu \mathrm{M}$ after $12 \mathrm{~h}$ incubation, and the $\mathrm{OD}_{600}$ of cell biomass reached its highest level at $28 \mathrm{~h}$ under a $50 \mu \mathrm{M}$ FA concentration. Moreover, the stimulation effect at $50 \mu \mathrm{M}$ was significantly $(p<0.05)$ higher than at other concentrations.

The effect of FA on the biocontrol activity of $B$. amyloliquefaciens subsp. plantarum YP1

YP1 growth in vitro was highest with $50 \mu \mathrm{M} \mathrm{FA}$, and this was thus chosen as the appropriate concentration for further analysis. Results of in vitro assays showed that treatments with $50 \mu \mathrm{M}$ of FA significantly enhanced the antagonism of YP1 towards RRD of $P$. notoginseng compared to the control treatment without the FA (personal communication). Thus, to perform an in-depth analysis on the effects of FA on the antagonistic activity of YP1, the relative expression levels of the genes involved in biocontrol activity were analysed in YP1 grown in the presence of FA. As illustrated in Fig. 8, the QRT-PCR results suggested that FA at $50 \mu \mathrm{M}$ could increase the transcription levels of all tested biocontrol-related genes, and significantly enhance the transcription levels of srfAA and sft genes in YP1, with increases of 2.4and 3.6-fold up-regulation compared to the control (without FA), respectively.

\section{Discussion}

The composition and abundance of endophytic communities with the same host plant varies not only from region to region but also among conditions within the same region (Deng et al. 2011; Yaish et al. 2015). Although our previous studies have shown that a diverse assemblage of bacterial endophytes are antagonistic towards RRD in $P$. notoginseng planted in Wenshan County, Yunnan Province, China (Ma et al. 2013), more extensive antagonistic resources were needed from endophyte populations of $P$. notoginseng in different growing regions. Therefore, we re-isolated bacterial endophytes from a distinct geographic area, Luxi County in Yunnan Province, and further evaluated in vitro their antagonism against RRDC, which will provide better insight into the diversity of AEB associated with $P$. notoginseng and a more comprehensive understanding of the biocontrol potential of endophytic bacteria harbored in $P$. notoginseng plants.

High rhizosphere competence has been recognized as a prerequisite for attracting rhizospheric inoculants with high biocontrol efficacy (Abdallah et al. 2018; Schreiter et al. 2014; Schreiter et al. 2018). It has been well established that chemotaxis to root exudates is a key bacterial trait contributing to high rhizosphere competence for inoculants under field conditions (Bais et al. 2006; Olanrewaju et al. 2019). Accordingly, chemotaxis is considered an important characteristic of a successful bacterial BCA candidate for soilborne pathogens (Allardmassicotte et al. 2016; Raina et al. 2019; Wu et al. 2015). Thus, identifying chemotactic bacterial populations from plant-associated microbiomes and understanding the underlying 
biological processes in this association is of the utmost importance for properly exploiting efficient BCA candidates for sustainable agriculture.

Buchan et al. (2010) developed and applied a molecular diagnostic tool-based on the gene cheA, which encodes the central regulator of bacterial chemotaxis-to characterise and track specific populations of native microbes with chemotaxis potential. The molecular technique based on the $c h e A$ gene, which serves as a functional molecular marker, has also shown potential for screening chemotaxis populations. Our previous work employed a cheA gene-based approach, focusing on chemotactic antagonistic bacteria against plant pathogens revealed that chemotaxis may be an important phenotype among soilassociated antagonistic bacteria (Li et al. 2012). However, little information exists about whether chemotaxis is a prevalent phenotype among plant-associated bacterial endophytes. Thus, the present study screened the chemotactic bacteria from the AEB associated with $P$. notoginseng by tracking $c h e A$ and analyzing the abundance and diversity of chemotactic AEB populations.

Phylogenetic analysis based on the 16S rRNA gene indicated that the chemotactic AEB associated with $P$. notoginseng were affiliated with three bacterial groups, comprising 15 genera of Actinobacteria, Firmicutes, and Proteobacteria (Fig. 1 and Table 1). The most abundant class in this assembly was Actinobacteria, with members of Bacillus representing the majority. The phylogenetic composition of the $P$. notoginseng-associated chemotactic bacteria, determined using 16S rRNA gene sequencing, differed from the communities in the rhizosphere and soil reported previously (Buchan et al. 2010; Li et al. 2012), indicating that the $c h e A$ gene profile abundance might vary among microbial assemblages in different ecological environments. This is the first study to examine and profile the genetic diversity of chemotaxis genes in medicinal plant-associated endophyte communities, and it substantially expands the known diversity of chemotactic-competent bacterial populations. Additionally, our results indicate that bacteria capable of chemotaxis are present and abundant among AEB-associated communities with $P$. notoginseng, and we thus propose that chemotaxis plays an important role in establishing and maintaining special $P$. notoginseng-endophyte associations. Therefore, studies on chemotaxis in CAEB communities are supposed to be necessary for a more comprehensive understanding of the ecological mechanisms and bacterial behaviors underpinning $P$. notoginseng-endophyte ecological associations.

To achieve a deeper understanding of chemotaxis of CAEB assemblages in P. notoginseng, we systematically quantified the chemotactic responses of these bacteria to organic acids. Organic acids, some of the important components in root exudates, have been reported to be the most common chemoattractants for many biocontrol microbes (el Zahar et al. 2014; Jones 1998). Thus, five OAs identified previously in the root exudates of $P$. notoginseng ( $L i$ et al. 2015)-citric acid, malic acid, fumaric acid, oxalic acid, and succinic acid-were selected to evaluate the chemotactic response of CAEB assemblages in $P$. notoginseng in this study. The results of our drop assays demonstrated that the CAEB assemblage in $P$. notoginseng exhibited positive chemotactic responses to all five tested OAs, although the strength of the chemotactic response varied (Fig. S2-6 and Table S1). Chemotaxis toward OAs is well documented among rhizobacteria (Ling et al. 2011; Tan et al. 2013; Yuan et al. 2015; Zhang et al. 2014), 
and has been demonstrated in some endophytic bacteria (Khare et al. 2018). Many reports highlight the roles that OAs play in plant-BCA interactions (el Zahar et al. 2014).

Based on our results and the literature, we propose that chemotaxis towards OAs is also involved in $P$. notoginseng-endophyte ecological associations. Here, our data provided the first evaluation of chemotactic behavior among natural populations of $P$. notoginseng-associated CAEB, with the different chemotaxis patterns observed towards the different OAs (Fig. S2-6 and Table S1). Furthermore, our results are highly consistent with the findings that many soil microbes respond differently towards different OAs (Ling et al. 2011; Tan et al. 2013). In this study, citric acid and fumaric acid were relatively stronger chemoattractants for most CAEB assemblages among all tested OAs. The stronger chemotaxis to citric acid and fumaric acid in root exudates might indicate that these compounds are the most effective bioattractants, and they may provide a competitive and selective advantage in the interaction between plants and microbes. Accordingly, we raised the possibility that citric acid and fumaric acid serve as major chemoattractants in root exudates of $P$. notoginseng that induce CAEB recruitment to the host. These data underline the need for future investigations aimed at evaluating the actual role of chemotaxis in response to these OAs in $P$. notoginseng-CAEB interactions.

To perform an in-depth characterization of the chemotactic response profiles of the CAEB strains toward the tested OAs, an hierarchical cluster analysis was employed, which revealed a striking diversity of responses to all five OAs (Figs. 3 and 4). It is clear that the chemotaxis responses of CAEB to the same tested substrate differ not only among genera but also among species and even within strains of a single species. The presence of multiple chemotaxis signal transduction pathways and a great diversity of chemoreceptors with novel sensory specificities in bacterial chemotaxis is well documented (Miller et al. 2009). Many bacterial species possess a large number of different chemoreceptors to mediate responses to different chemical stimuli (Yang and Briegel 2020). The diversity in chemotaxis signal transduction systems and chemoreceptors probably explains the diverse response profiles of the CAEB to different OAs. The discovery that CAEB respond to five OAs via chemotaxis expands the repertoire of known chemotactic bacteria and is a proof that endophytic bacteria show a behavioral response to OAs in medicinal plants, which had previously not been examined. Further identification of bacterial chemoreceptors for OAs will provide a more thorough understanding of the OA chemosensory system and allow researchers to compare the diversity of chemotaxis pathways and chemoreceptors identified in silico.

Many studies have focused on demonstrating the regulatory functions of OAs involved in the interaction between plants and rhizobacteria. However, few studies have investigated the effects of OAs on the antagonistic activities of endophytic bacteria concerning the relationship between OAs and biocontrol ability of endophytes in the rhizosphere. Additionally, in light of our results showing that all 32 representative strains of CAEB in $P$. notoginseng exhibited positive chemotactic responses to all tested OAs, we postulate that chemotaxis towards OAs is a biocontrol trait of CAEB assemblages in $P$. notoginseng. To address this question, we first investigated the effects of OAs on chemotaxis in the representative strain $B$. amyloliquefaciens subsp. plantarum YP1, selected from the CAEB assemblage. 
Our results suggested that all tested OAs induced positive chemotaxis in YP1 (Fig. 5), and this matched the results of the drop assay assessment of chemotaxis (Fig. S2-6). It is also evident from the results that the effects of OAs on the chemotactic response of YP1 differed depending on the OAs used.

Interestingly, the effects of CA and FA on chemotaxis in YP1 were concentration-dependent (Fig. 5A and B), and the chemotactic response was strongest using FA at $50 \mu \mathrm{M}$ (Fig. 5A).

Furthermore, our results were highly consistent with earlier reports that some beneficial bacteria associated with plants exhibit chemotaxis toward OAs in a dose-dependent manner (Liu et al. 2019; Zhang et al. 2013; Zhang et al. 2014). As expected, the qRT-PCR on cheA relative gene expression levels in YP1 demonstrated that FA at $50 \mu \mathrm{M}$ induced the highest increase in che $A$ gene transcript expression of all the $O A$ treatments at that concentration (Fig. 6A), which further confirms that FA has a strong chemotaxis effect in YP1 (Fig. 5A). The capacity of a compound to elicit a chemotactic bacterial response might be related to its nutritional properties. Many studies have shown that OAs as main chemoattractants in REs have significant stimulatory effects on the growth of microbes interacting with plants and can be used as nutrients or signals by some beneficial microbes (Liu et al. 2019; Wu et al. 2017; Zhang et al. 2013). Here, we hypothesized that OAs are used as a nutritional basis for CAEB strains to support their growth. Following the observation that FA is the strongest chemoattractant to YP1, we further selected FA as the target to test the effect of OAs on the growth of YP1. As expected, the results obtained in vitro suggested that FA at different concentrations promoted YP1 growth to different degrees (Fig. 7). Importantly, we confirmed that YP1 growth significantly improved when FA was its sole carbon source, and peaked when the concentration of FA was $50 \mu \mathrm{M}$ (Fig. 7). These findings corroborate the results of Ling et al. (2011), who showed that OAs can effectively enhance the growth of biocontrol microbes. Zhang et al. (2014) also demonstrated that certain organic acids (oxalic acid, malic acid, and citric acid) could be used as nutritional sources for the beneficial fungus Trichoderma harzianum T-E5 to reinforce its population on cucumber roots.

Accumulating evidence has indicated that the biocontrol effect of some antagonistic microbes on plant diseases mainly results from the addition of OAs that stimulate the growth of these strains (Ling et al. 2011; Tan et al. 2013; Yuan et al. 2015; Zhang et al. 2014). The observation presented here, showing that FA can stimulate the growth and chemotactic ability of YP1, led us to think that the antagonistic activity of YP1 might also be affected by FA. To verify this hypothesis, we carried out a series of experiments to determine the relative contribution of FA to the antagonistic activity of YP1. It was observed that the addition of FA could enhance the transcriptional expression levels of selected biocontrol-related genes in YP1 (Fig. 8) and increase the antagonistic activity of YP1 in vitro (personal communication). Initially, we measured the transcript levels of selected biocontrol-related genes at different time points $(0,14,28$, and $36 \mathrm{~h}$ ) after incubation. The highest increase in the relative gene expression levels of most tested genes compared to the control was observed in YP1 treated with FA after $28 \mathrm{~h}$ (personal communication). As mentioned above, the maximum cell biomass was measured at $28 \mathrm{~h}$ of YP1 growth under the FA treatment (Fig. 7). In light of these data, we putatively selected 28-h incubation as the key time point for evaluating the effect of FA on the expression levels of biocontrol genes in YP1. 
Lipopeptides (LPs) produced by Bacillus are well-known to be important factors in the antagonistic activities against pathogens (Chen et al. 2013). Recent studies have indicated that OAs significantly increase LP production in the rhizosphere, resulting in a population increase of $B$. amyloliquefaciens S499 in the root (Nihorimbere et al. 2012). Additionally, it has been demonstrated that the transcription level of the sft gene involved in LP production can be significantly enhanced by adding pectin, a kind of tobacco root extract, as it might help increase the biocontrol activity of $B$. amyloliquefaciens SQY162 against tobacco bacterial wilt (Wu et al. 2015). It has been demonstrated that LPs produced by $B$. amyloliquefaciens FZB42 might be most important for colonizing plant roots (Fan et al. 2011) and the antibiotic effects towards $R$. solanacearum (Chen et al. 2013). Accordingly, significant increases in the expression of genes (srfAA, sft) involved in LP production and synthesis in YP1 by applying FA (Fig. 8) might enhance the colonization ability of YP1, so we suggest that the biocontrol activity of YP1 against RRD might be enhanced in the presence of FA due to enhanced LP production or synthesis and colonization. However, the molecular mechanism underlying this enhancement effect by FA on the biocontrol activity in YP1 needs to be explored further. The findings presented here highlight the promoting effects of FA on the growth, chemotaxis, and antagonism of YP1 and expression of its biocontrol-related genes, which indicate that chemotaxis to OAs in $P$. notoginseng-associated CAEB may directly contribute to their antagonism against RRD of $P$. notoginseng.

Taken together, this is the first study to examine and profile the genetic diversity of chemotaxis gene che $A$ in endophytic populations associated with $P$. notoginseng. Evidence was presented that there is a diverse assemblage of chemotactic bacteria in endophytic antagonists associated with $P$. notoginseng, and this lays the foundations for further understanding the community structure and functional characteristics of chemotactic-competent microbes in the $P$. notoginseng-associated endophytic antagonists. Our data provide the first evaluation of chemotactic behavior among natural populations of $P$. notoginsengassociated AEB. This finding could increase our understanding of how biocontrol organisms respond to OAs and provide new information to create a more comprehensive understanding of the ecological roles that OAs play in plant-microbe interactions. This work will identify the potential candidates with a competitive advantage via chemotaxis mechanisms for developing new strategies to better control RRD in $P$. notoginseng from an ecological point of view.

\section{Declarations}

\section{Acknowledgements}

This work was supported by the NSFC(31960022, 31870091), the Department of Science and Technology of Yunnan Province (202001BB050072, 2019ZG00901,YNWR-CYJS-2019-042).

\section{Authors' contributions}

Li Ma, wrote the manuscript and funding acquisition, designed the article. Wu-Qin Wang, analysed data, drew the figures of this manuscript. Rui Shi and Xue-Mei Zhang, revised the manuscript, collected the literature, Xin Li and Yu-Sen Yang, added references and participated in revising the manuscript. Ming He 
Mo, contributed to the writing of the manuscript, suggested and added references, critically revised the manuscript. All authors have read and approved the manuscript.

\section{Data availability}

The 16S rRNA gene sequences that support the findings of this study have been deposited in GenBank with the accession numbers listed in Table 1 shown in the manuscript.

\section{Compliance with ethical standards}

\section{Conflict of interest}

The authors declare that they have no known competing financial interests or personal relationships that could have appeared to influence the work reported in this paper.

\section{References}

1. Abdallah DB, Frikhagargouri O, Tounsi S (2018) Rizhospheric competence, plant growth promotion and biocontrol efficacy of Bacillus amyloliquefaciens subsp. plantarum strain 32a. Biol Control 124:61-67

2. Adler $\mathrm{J}$ (1973) A method for measuring chemotaxis and use of the method to determine optimum conditions for chemotaxis by Escherichia coli. Microbiol 74:77-91

3. Allardmassicotte R, Tessier L, Lecuyer F, Lakshmanan V, Lucier J, Garneau D, Caudwell I, Vlamakis H, Bais HP, Beauregard PB (2016) Bacillus subtilis early colonization of Arabidopsis thaliana roots involves multiple chemotaxis receptors. mBio 7:e01664-e01616

4. Baermann $\mathrm{G}$ (1917) ine eifache methode zur auffindung von anklyostomum (Nematoden) larven in erdproben. Geneeskunding Tijdschrift voor Nederlandsch-Indië 57:131-137

5. Bais HP, Fall R, Vivanco JM (2004) Biocontrol of Bacillus subtilis against infection of Arabidopsis roots by Pseudomonas syringaeis facilitated by biofilm formation and surfactin production. Plant Physiol 134:307-319

6. Bais HP, Weir TL, Perry LG, Gilroy S, Vivanco JM (2006) The role of root exudates in rhizosphere interactions with plants and other organisms. Annu Rev Plant Biol 57:233-266

7. Barret M, Morrissey JP, O'Gara F (2011) Functional genomics analysis of plant growth-promoting rhizobacterial traits involved in rhizosphere competence. Biol Fertil Soils 47:729-743

8. Bi S, Jin F, Sourjik V (2018) Inverted signaling by bacterial chemotaxis receptors. Nat Commun 9:2927

9. Buchan A, Crombie B, Alexandre G (2010) Temporal dynamics and genetic diversity of chemotacticcompetent microbial populations in the rhizosphere. Environ Microbiol 12:3171-3184

10. Chen Y, Yan F, Chai Y, Liu H, Kolter R, Losick R, Guo J (2013) Biocontrol of tomato wilt disease by Bacillus subtilis isolates from natural environments depends on conserved genes mediating biofilm 
formation. Environ Microbiol 15:848-864

11. Chen YJ, Wang YY, Feng GQ, Li ZY (2001) Relationship between root rot of Panax notoginseng and ecological conditions. Yunnan Agric Sci Technol 6:33-35

12. Compant S, Clement C, Sessitsc A (2010) Plant growth-promoting bacteria in the rhizo- and endosphere of plants: their role, colonization. Soil Biol Biochem 42:669-678

13. De Silva NI, Brooks S, Lumyong S, Hyde KD (2019) Use of endophytes as biocontrol agents. Fungal Biol Rev 33:133-148

14. Deng ZS, Zhao LF, Kong ZY, Yang WQ, Lindstrom K, Wang ET, Wei G (2011) Diversity of endophytic bacteria within nodules of the Sphaerophysa salsula in different regions of Loess Plateau in China. FEMS Microbiol Ecol 76:463-475

15. el Zahar HF, Santaella C, Heuli, Achouak W (2014) Root exudates mediated interactions belowground. Soil Biol Biochem 77:69-80

16. Fan B, Chen X, Budiharjo A, Bleiss W, Vater J, Borriss R (2011) Efficient colonization of plant roots by the plant growth promoting bacterium Bacillus amyloliquefaciens FZB42, engineered to express green fluorescent protein. J Biotechnol 151:303-311

17. Greer-Phillips SE, Alexandre G, Taylor BL, Zhulin IB (2003) Aer and Tsr guide Escherichia coli in spatial gradients of oxidizable substrates. Microbiol 49:2661-2667

18. Guo HB, Cui XM, An N, Cai GP (2010) Sanchi ginseng (Panax notoginseng (Burkill) F.H. Chen) in China: Distribution, cultivation and variations. Genet Resour Crop Evolut 57:453-460

19. Jones DL (1998) Organic acids in the rhizosphere: a critical review. Plant Soil 205:25-44

20. Joshi R, Gardener BB (2006) Identification and characterization of novel genetic markers associated with biological control activities in Bacillus subtilis. Phytopathol 96:145-154

21. Khare E, Mishra J, Arora NK (2018) Multifaceted interactions between endophytes and plant: developments and prospects. Front Microbiol 15:2732

22. Kim OS, Cho YJ, Lee K, Yoon SH, Kim MNaH, Park SC, Jeon YS, Lee JH, Yi H, Won S, Chun J (2012) Introducing EzTaxon-e: a prokaryotic 16S rRNA gene sequence database with phylotypes that represent uncultured species. Int J Syst Evol Microbiol 62:716-721

23. King EO, Ward M, Raney DE (1954) Two simple media for the demonstration of pyocyanin and fluorescein. J Lab Clin Med 44:301-307

24. Kumar S, Stecher G, Tamura K (2016) MEGA7: Molecular Evolutionary Genetics Analysis version 7.0 for bigger datasets. Mol Biol Evol 33:1870-1874

25. Lane DJ (1991) 16S/23S rRNA sequencing. In: Stackebrandt E, Goodfellow M (eds) Nucleic acid techniques in bacterial systematics. Wiley, New York, pp 115-175

26. Li P, Ma L, Feng YL, Mo MH, Yang FX, Dai HF, Zhao YX (2012) Diversity and chemotaxis of soil bacteria with antifungal activity against Fusarium wilt of banana. J Ind Microbiol Biot 39:14951505 
27. Li Z, Min Q, Sun JJ, Zu Y (2015) Effect of As stress on the growth, the root As contents and root exudates in 2-year-old Panax notoginseng. Journal of Beijing University of Agriuculture 30:86-91

28. Ling N, Raza W, Ma J, Huang Q, Shen Q (2011) Identification and role of organic acids in watermelon root exudates for recruiting Paenibacillus polymyxa SQR-21 in the rhizosphere. Eur J Soil Biol 47:374-379

29. Liu F, Wen XS (2006) Progress in relationship between root exudates and rhizospheric microorganism. Food Drug 8:37-40

30. Liu X, Zhang K, Liu Y, Xie Z, Zhang C (2019) Oxalic acid from sesbania rostrata seed exudates mediates the chemotactic response of Azorhizobium caulinodans ORS571 using multiple strategies. Front Microbiol 10:2727

31. Livak KJ, Schmittgen TD (2001) Analysis of relative gene expression data using real-time quantitative PCR and the 2(-Delta Delta C(T)) method. Methods 25:402-408

32. Luo WF, Yu SF, He CF, Li ZY, Wang CL, Cui XM (1997) On the combined infection of root rot pathogens on Panax notoginseng. Acta Phytopathol Sin 27:85-91

33. Ma L, Cao YH, Cheng MH, Huang Y, Mo MH, Wang Y, Yang JZ, Yang FX (2013) Phylogenetic diversity of bacterial endophytes of Panax notoginseng with antagonistic characteristics towards pathogens of root-rot disease complex. Antonie Van Leeuwenhoek 103:299-312

34. Ma L, Zheng SC, Zhang TK, Liu ZY, Wang XJ, Zhou XK, Yang CG, Duo JL, Mo MH (2018) Effect of nicotine from tobacco root exudates on chemotaxis, growth, biocontrol efficiency, and colonization by Pseudomonas aeruginosa NXHG29. Antonie Van Leeuwenhoek 111:237-1257

35. Maechler M, Rousseeuw P, Struyf A, Hubert M, Hornik K (2017) Cluster: Cluster Analysis Basics and Extensions. R package version 2.0. 6. https://www.r-project.org/

36. Maidak BL, Olsen GJ, Larsen N, Overbeek R, Mc-Caughey MJ, Woese CR (1997) The RDP (ribosomal database project). Nucleic Acids Res 25:109-110

37. Mao ZS, Long YJ, Zhu SS, Chen ZJ, Wei FG, Zhu YY (2013) Advances in root rot pathogen of Panax notoginseng research. J Chin Med Mater 36:2051-2054

38. Miao ZQ, Li SD, Liu XZ, Hen YJ, Li YH, Wang Y, Guo RJ, Xia ZY, Zhang KQ (2006) The causal microorganisms of Panax notoginseng root-rot disease. Sci Agric Sin 39:1371-1378

39. Miller LD, Russell MH, Alexandre G (2009) Diversity in bacterial chemotactic responses and niche adaptation. Adv Appl Microbiol 66:53-75

40. Nihorimbere V, Cawoy H, Seyer A, Brunelle A, Thonart P, Ongena M (2012) Impact of rhizosphere factors on cyclic lipopeptide signature from the plant beneficial strain Bacillus amyloliquefaciens S499. FEMS Microbiol Ecol 79:176-191

41. Olanrewaju OS, Ayangbenro AS, Glick BR, Babalola 00 (2019) Plant health: feedback effect of root exudates-rhizobiome interactions. Appl Microbiol Biot 103:1155-1166

42. Ongena $M$, Jacques $P$ (2008) Bacillus lipopeptides: versatile weapons for plant disease biocontrol. Trends Microbiol 16:115-125 
43. Raaijmakers JM, Paulitz TC, Steinberg C, Alabouvette C, Moenne-Loccoz Y (2009) The rhizosphere: a playground and battlefield for soilborne pathogens and beneficial microorganisms. Plant Soil 321:341-361

44. Raina J, Fernandez V, Lambert BS, Stocker R, Seymour JR (2019) The role of microbial motility and chemotaxis in symbiosis. Nat Rev Microbiol 17:284-294

45. Repik A, Rebbapragada A, Johnson MS, Haznedar JO, Zhulin IB, Taylor BL (2000) PAS domain residues involved in signal transduction by the Aer redox sensor of Escherichia coli. Mol Microbiol 36:806-816

46. Rosenblueth M, Martínez-Romero E (2006) Bacterial endophytes and their interactions with hosts. Mol Plant Microbe Interact 19:827-837

47. Rudrappa T, Czymmek KJ, Paré PW, Bais HP (2008) Root-secreted malic acid recruits beneficial soil bacteria. Plant Physiol 148:1547-1556

48. Samanta SK, Bhushan B, Chauhan A, Jain RK (2000) Chemotaxis of a Ralstonia sp. SJ98 toward different nitroaromatic compounds and their degradation. Biochem Bioph Res Co 269:117-123

49. Schreiter S, Sandmann M, Smalla K, Grosch R (2014) Soil type dependent rhizosphere competence and biocontrol of two bacterial inoculant strains and their effects on the rhizosphere microbial community of field-grown lettuce. PLoS ONE 9:e103726

50. Schreiter S, Babin D, Smalla K, Grosch R (2018) Rhizosphere competence and biocontrol effect of Pseudomonas sp. RU47 independent from plant species and soil type at the field scale. Front Microbiol 9:97

51. Sha MC, Zhou YF, Zhang HZ, Li Y, Qin Q (2018) Study on differences of chemical components in different parts of Panax notoginseng. Mod Chin Med 20:832-836

52. Tan S, Yang C, Mei X, Shen S, Raza W, Shen Q, Xu Y (2013) The effect of organic acids from tomato root exudates on rhizosphere colonization of Bacillus amyloliquefaciens T-5. Appl Soil Ecol 64:1522

53. Wang CL, Cui XM, Li ZY, He CF, Yu SF, Luo WF (1998) Studies on relationship between root rot on Panax notoginseng Burk. F. H. Chen and its environmental conditions. Chin J Chin Materia Medica 23:714-716

54. Wang Y, Lu ZX, Wu H, Lv FX (2009) Study on the antibiotic activity of microcapsule curcumin against foodborne pathogens. Int J Food Microbiol 136:71-74

55. Wu H, Wu L, Zhu Q, Wang J, Qin X, Xu J, Kong L, Chen J, Lin S, Khan MU, Amjad H, Lin W (2017) The role of organic acids on microbial deterioration in the Radix pseudostellariae rhizosphere under continuous monoculture regimes. Sci Rep 7:1-13

56. Wu K, Fang Z, Guo R, Pan B, Shi W, Yuan S, Guan H, Gong M, Shen B, Shen Q (2015) Pectin enhances bio-control efficacy by inducing colonization and secretion of secondary metabolites by Bacillus amyloliquefaciens SQY 162 in the rhizosphere of tobacco. PLoS ONE 10:e0127418

57. Xu C, Wang W, Wang B, Zhang T, Cui X, Pu Y, Li N (2019) Analytical methods and biological activities of Panax notoginseng saponins. Recent trends J Ethnopharmacol 236:443-465 
58. Yaish MW, Antony I, Glick BR (2015) solation and characterization of endophytic plant growthpromoting bacteria from date palm tree (Phoenix dactylifera L.) and their potential role in salinity tolerance. Antonie Van Leeuwenhoek 107:1519-1532

59. YangW, Briegel A (2020) Diversity of bacterial chemosensory arrays. Trends Microbiol 28:68-80

60. Yuan J, Zhang N, Huang Q, Raza W, Li R, Vivanco JM, Shen Q (2015) Organic acids from root exudates of banana help root colonization of PGPR strain Bacillus amyloliquefaciens NJN-6. Scientific reports 5:13438

61. Zhang F, Meng X, Yang X, Ran W, Shen Q (2014) Quantification and role of organic acids in cucumber root exudates in Trichoderma harzianum T-E5 colonization. Plant Physiol Bioch 83:250-257

62. Zhang N, Wang D, Liu Y, Li S, Shen Q, Zhang R (2013) Effects of different plant root exudates and their organic acid components on chemotaxis, biofilm formation and colonization by beneficial rhizosphere-associated bacterial strains. Plant soil 374:689-700

\section{Figures}




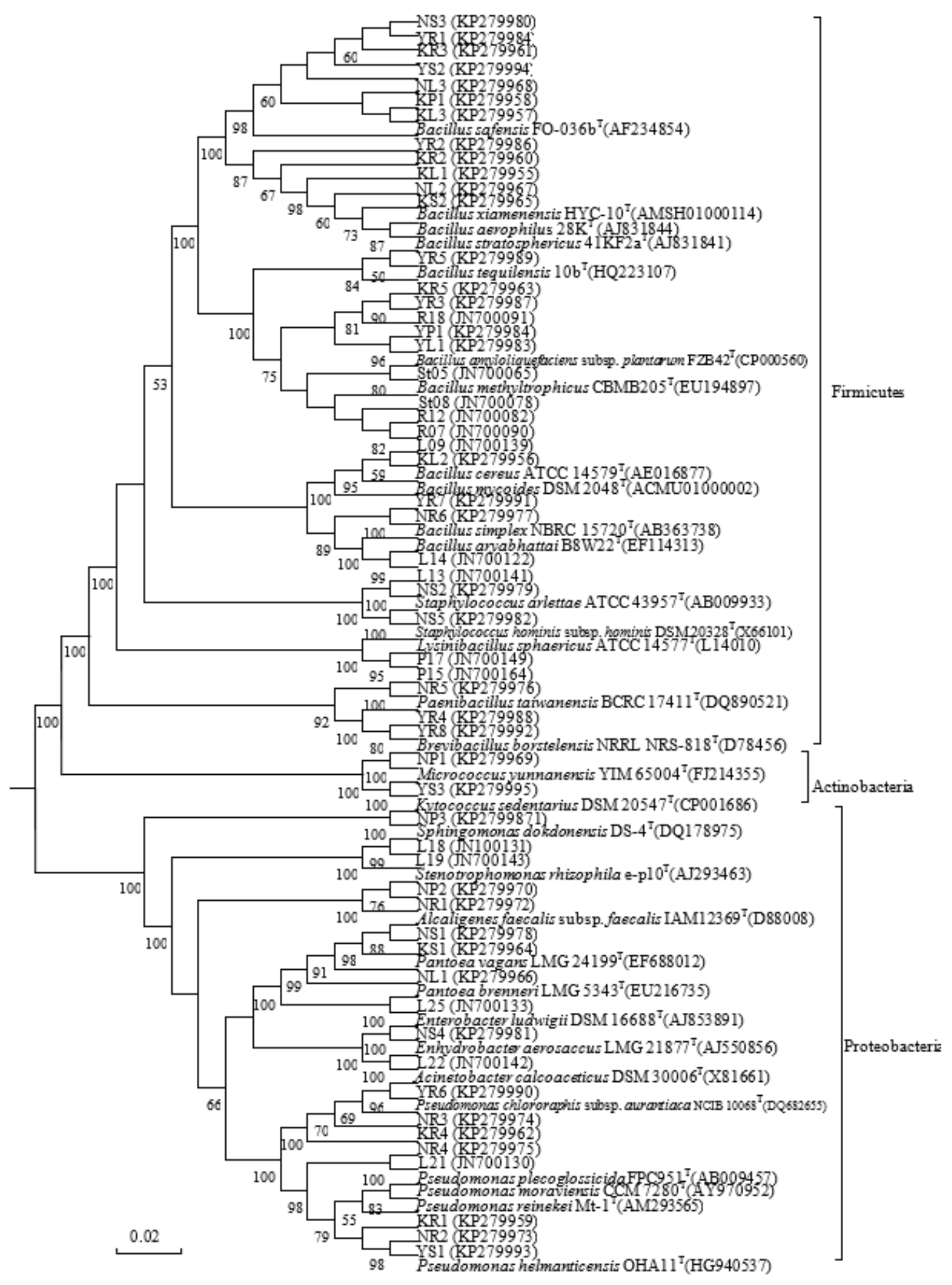

\section{Figure 1}

Neighbor-joining phylogenetic tree of chemotactic antagonistic endophytic bacteria associated with rootrot disease in Panax notoginseng and their closest relatives basing on the 16S rRNA gene sequences. The significance of each branch is indicated by a bootstrap value calculated for 1,000 subsets. Only values above $50 \%$ were shown. The scale bar represents 0.02 substitutions per base position. Accession numbers are given in parentheses. 


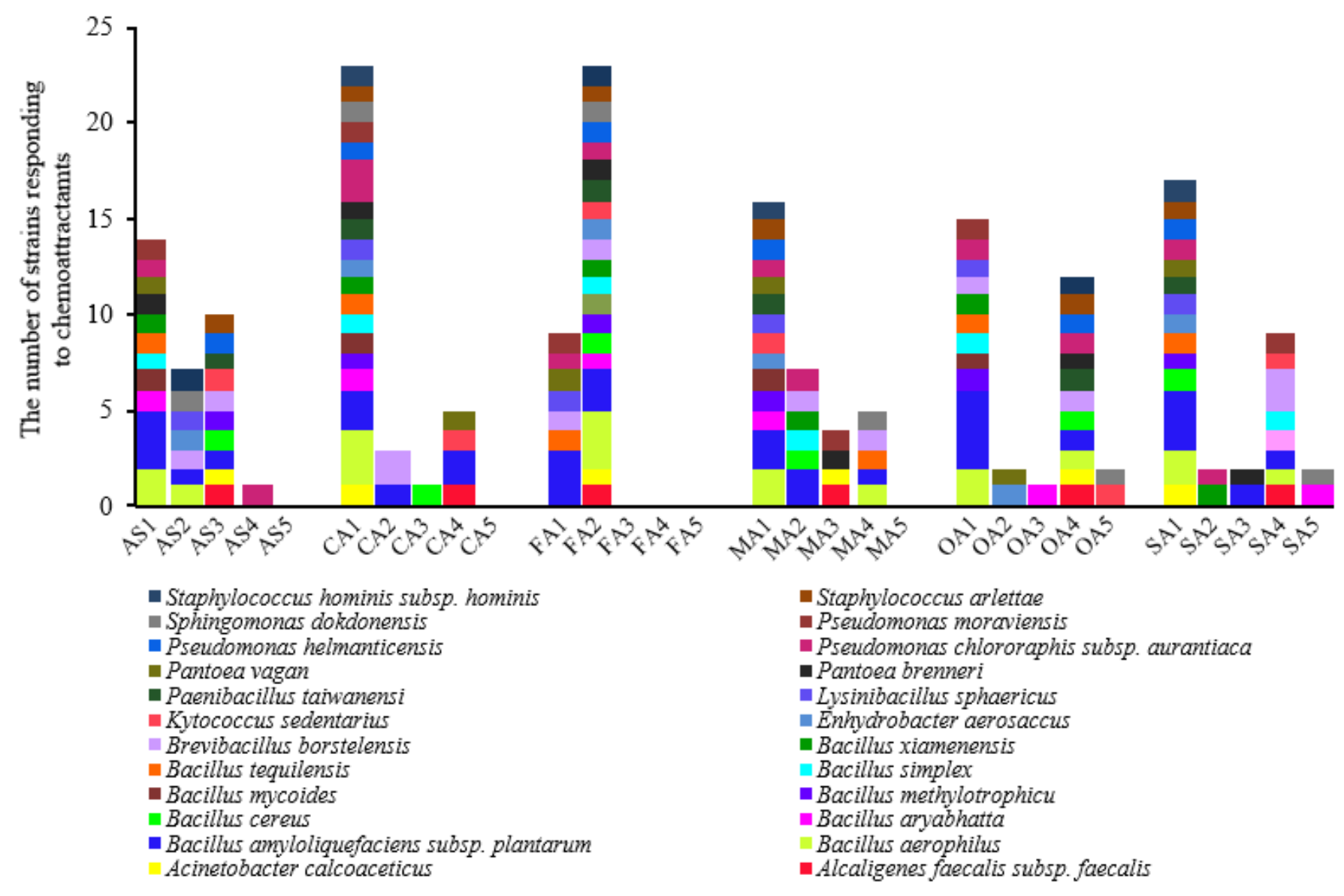

Figure 2

The relative proportions of species of chemotactic antagonistic endophytic bacteria associated with rootrot disease in Panax notoginseng responding to five organic acids. As such, this figure provides an overview of the chemotactic proportion according to the response score by the community to each chemoattractants. For more details on each taxon responding to individual chemoattractants, see Supplementary Table S1. The species among the chemotactic antagonistic endophytic bacterial community associated with P. notoginseng are denoted by the colors in the legend. The following organic acids were used: citric acid (CA), fumaric acid (FA), malic acid (MA), oxalic acid (OX), and succinic acid $(\mathrm{SA})$. The strength of the chemotactic response was quantified by measuring the diameter of the chemotactic ring and scored on a scale as described previously (Greer-Phillips et al., 2003; Repik et al., 2000). In this figure, the scale was denoted as $1-5$ followed by the name of organic acid on the horizontal $x$-axis from very strong response ( $>51 \mathrm{~mm}$, denoted as 1$)$, stronger response $(31-50 \mathrm{~mm}, 2)$, strong response (21-30 mm, 3), weak response (1-20 mm, 4), and "-" no response (5). 


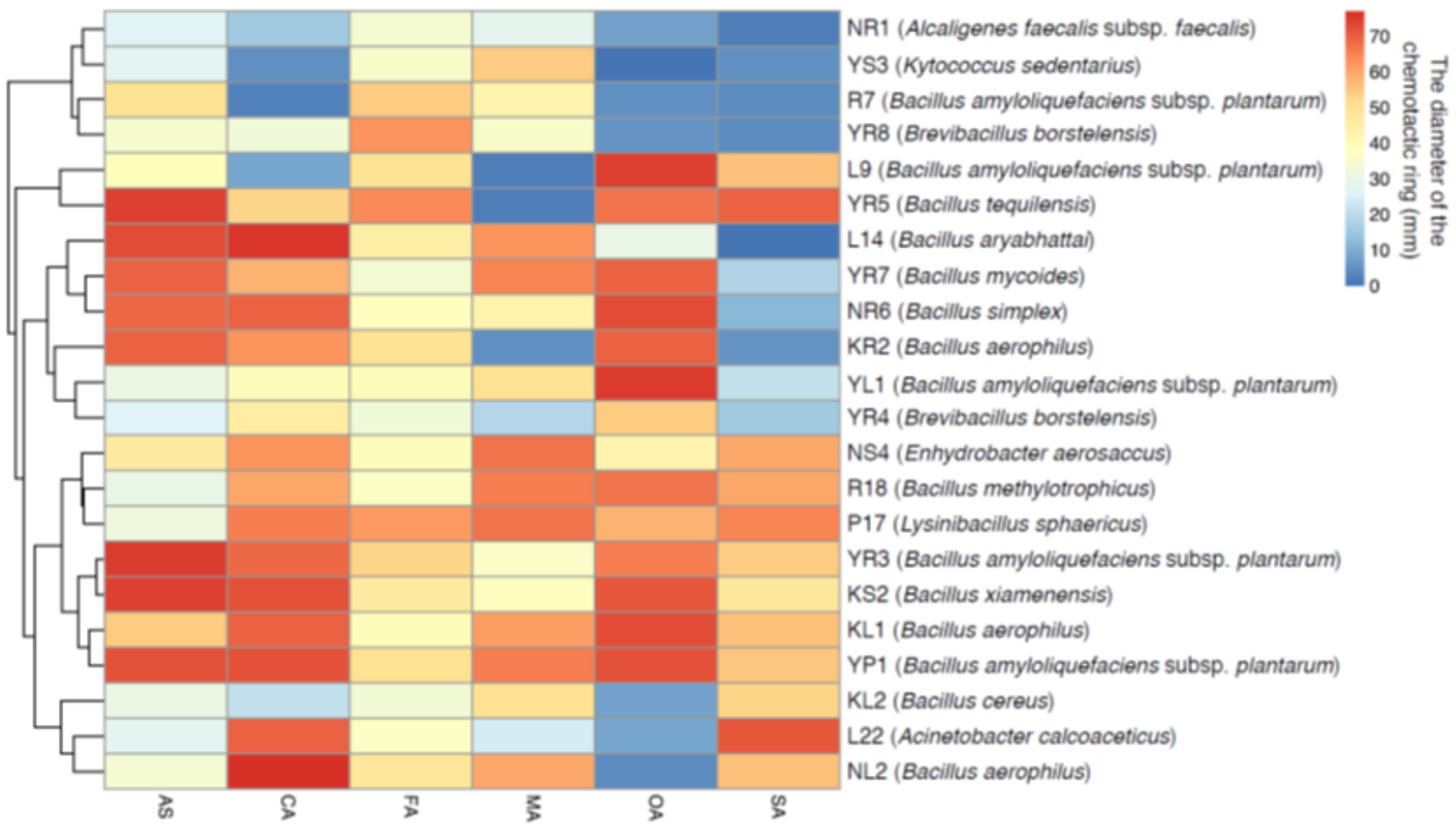

\section{Figure 3}

Hierarchical clustering (left panel) and heat map (right panel) of chemotactic response profiles to five organic acids across the representative chemotactic antagonistic endophytic bacteria associated with Panax notoginseng. The strength of the bacterial chemotactic response was quantified by measuring the diameter of the chemotactic ring, which are color-coded as shown to the right of the heatmap. For tested OAs included: citric acid (CA), fumaric acid (FA), malic acid (MA), oxalic acid (OX), and succinic acid (SA). The heat map displays diverse chemotactic response profiles among each species (rows) to each OA (column). 


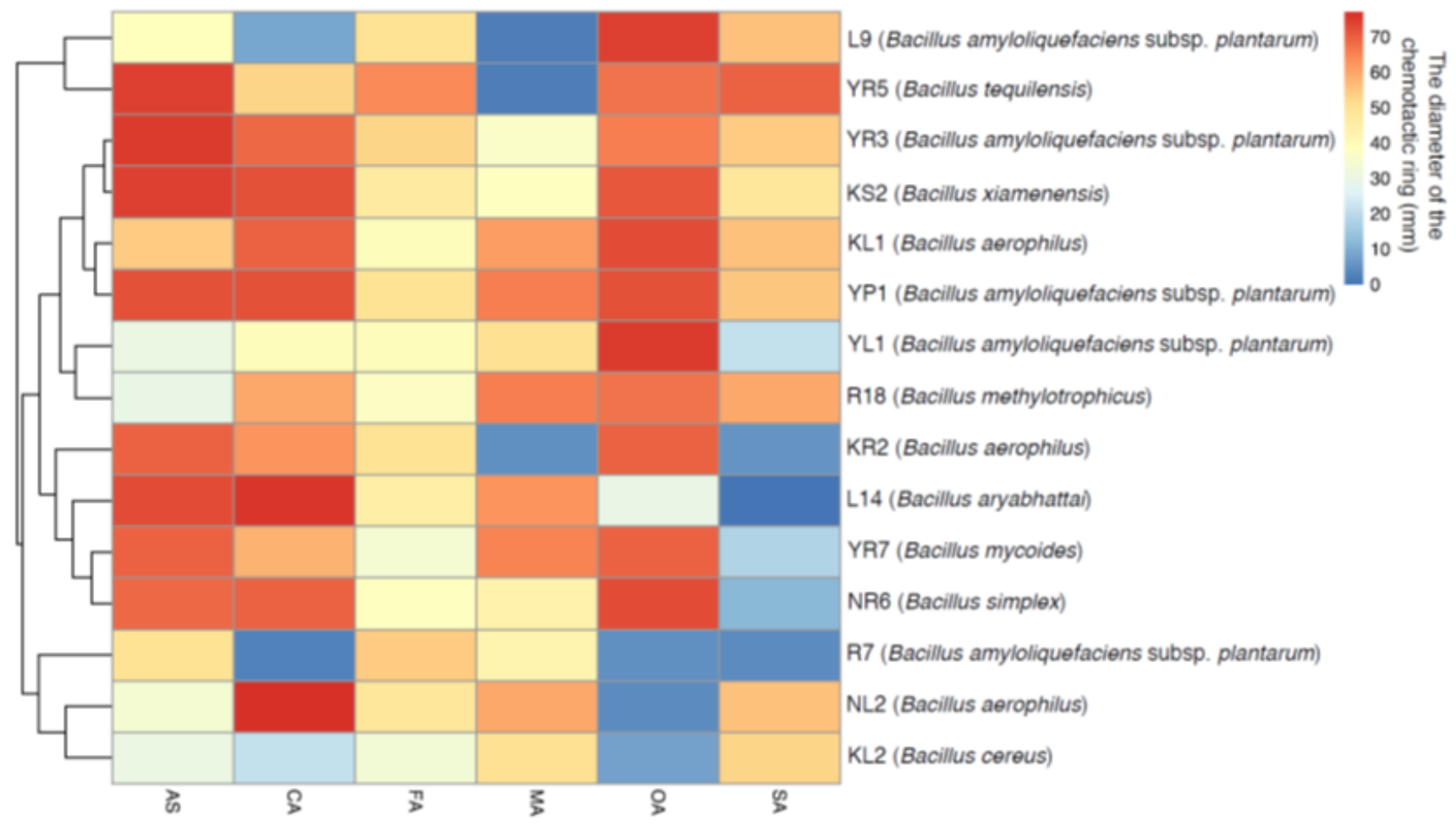

\section{Figure 4}

Hierarchical clustering (left panel) and heat map (right panel) of chemotactic response profiles to five organic acids across the genus Bacillus of representative chemotactic antagonistic endophytic bacteria associated with Panax notoginseng. The strength of the bacterial chemotactic response was quantified by measuring the diameter of the chemotactic ring, which is color-coded as shown to the right of the heatmap. The following OAs were used: citric acid (CA), fumaric acid (FA), malic acid (MA), oxalic acid (OX), and succinic acid (SA). The heat map displays diverse chemotactic response profiles among each species (rows) to each OA (column). 
A

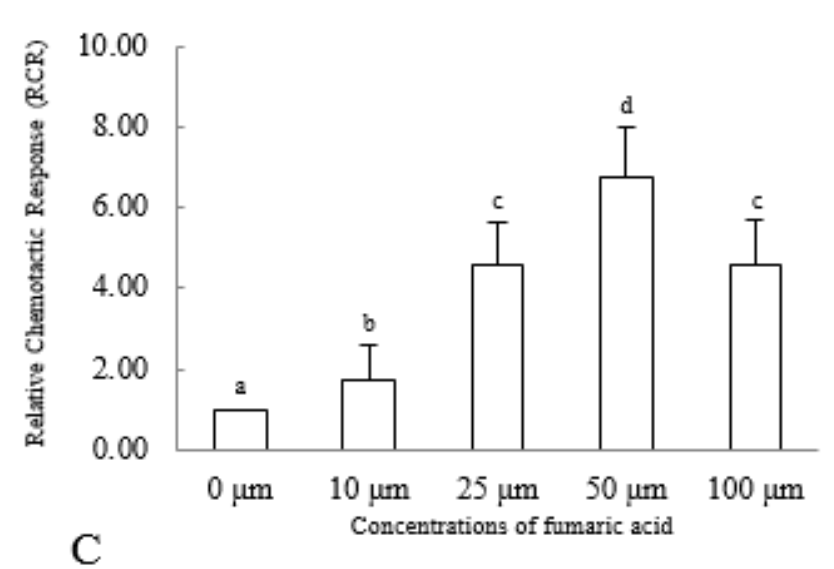

$\mathrm{C}$

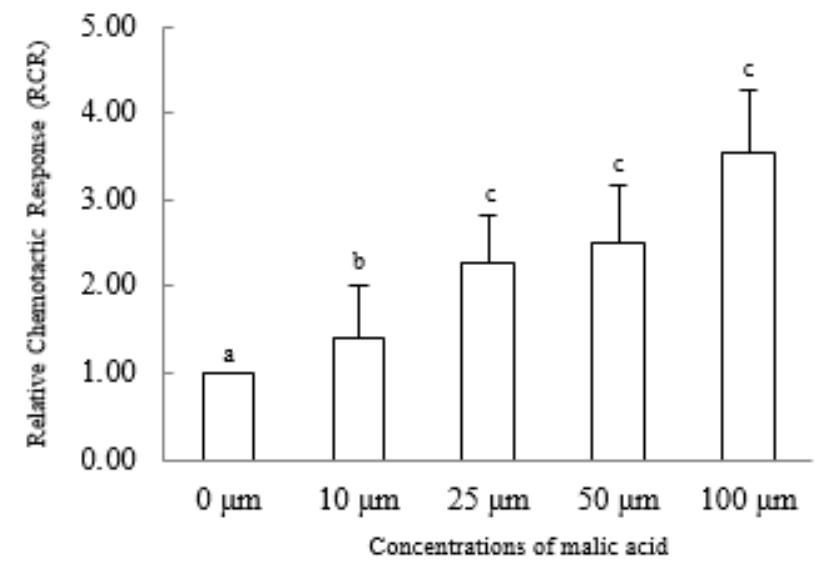

$\mathrm{E}$

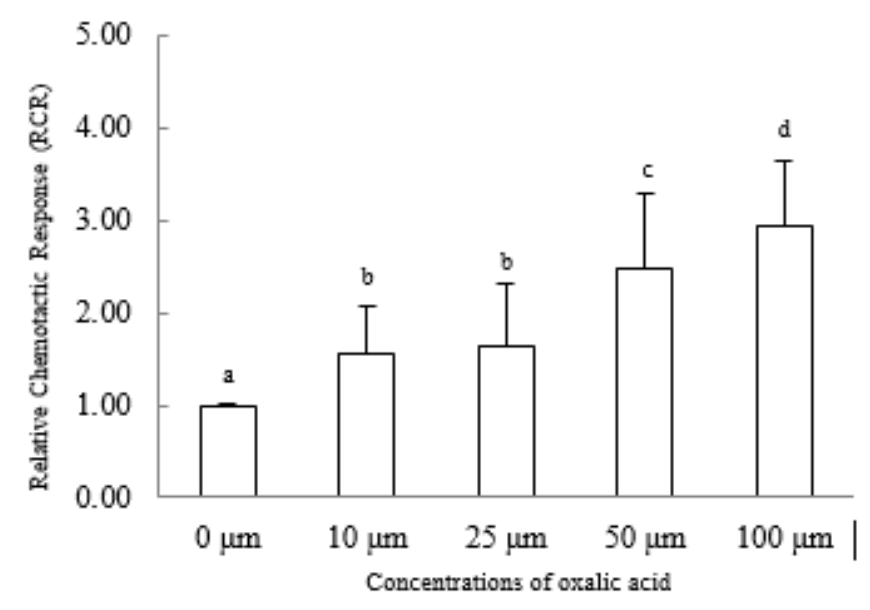

B
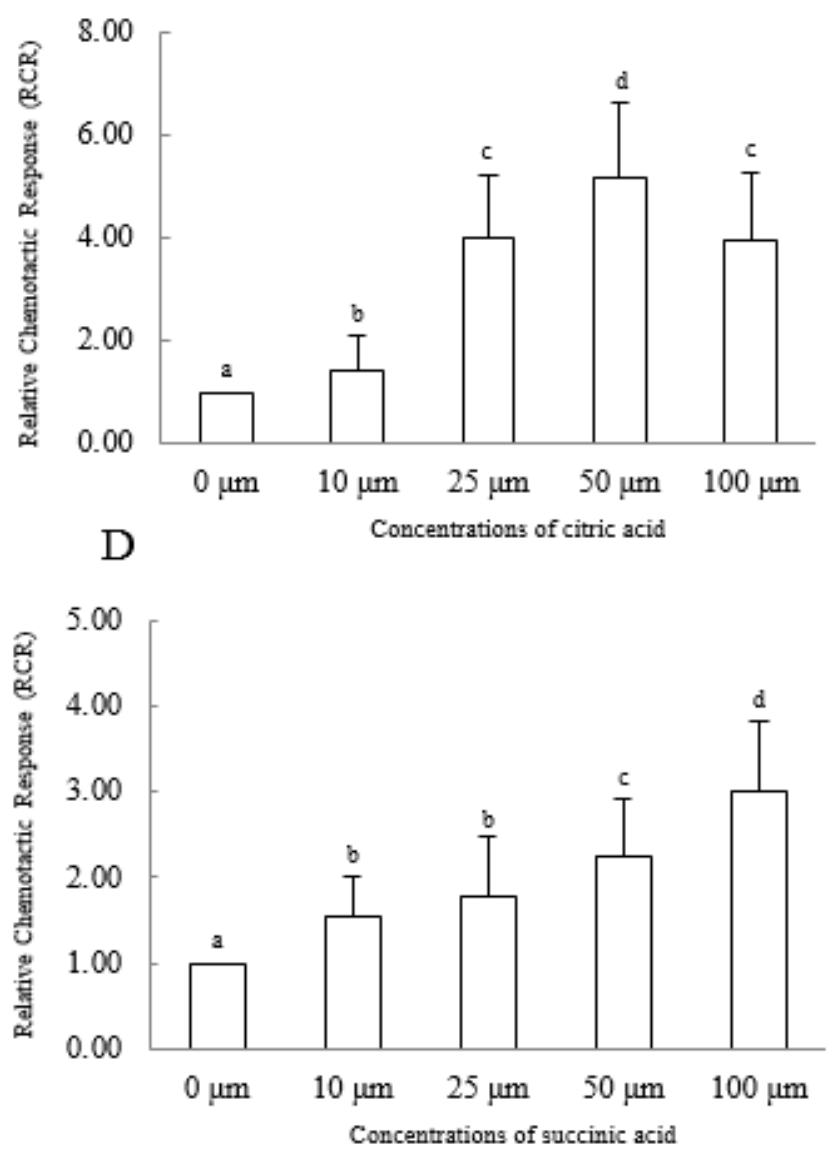

\section{Figure 5}

Chemotactic responses of Bacillus amyloliquefaciens subsp. plantarum YP1 to different organic acids at different concentrations evaluated by capillary assay. The chemotaxis buffer was supplemented with citric acid (CA), fumaric acid (FA), malic acid (MA), oxalic acid (OX), and succinic acid (SA) at final concentrations of $10,25,50,100 \mu \mathrm{M}$ each. Bars indicate standards errors from the means of three 
replicates. Letters above the columns represent significant difference for each treatment according to Duncan's multiple range test $(p<0.05)$.

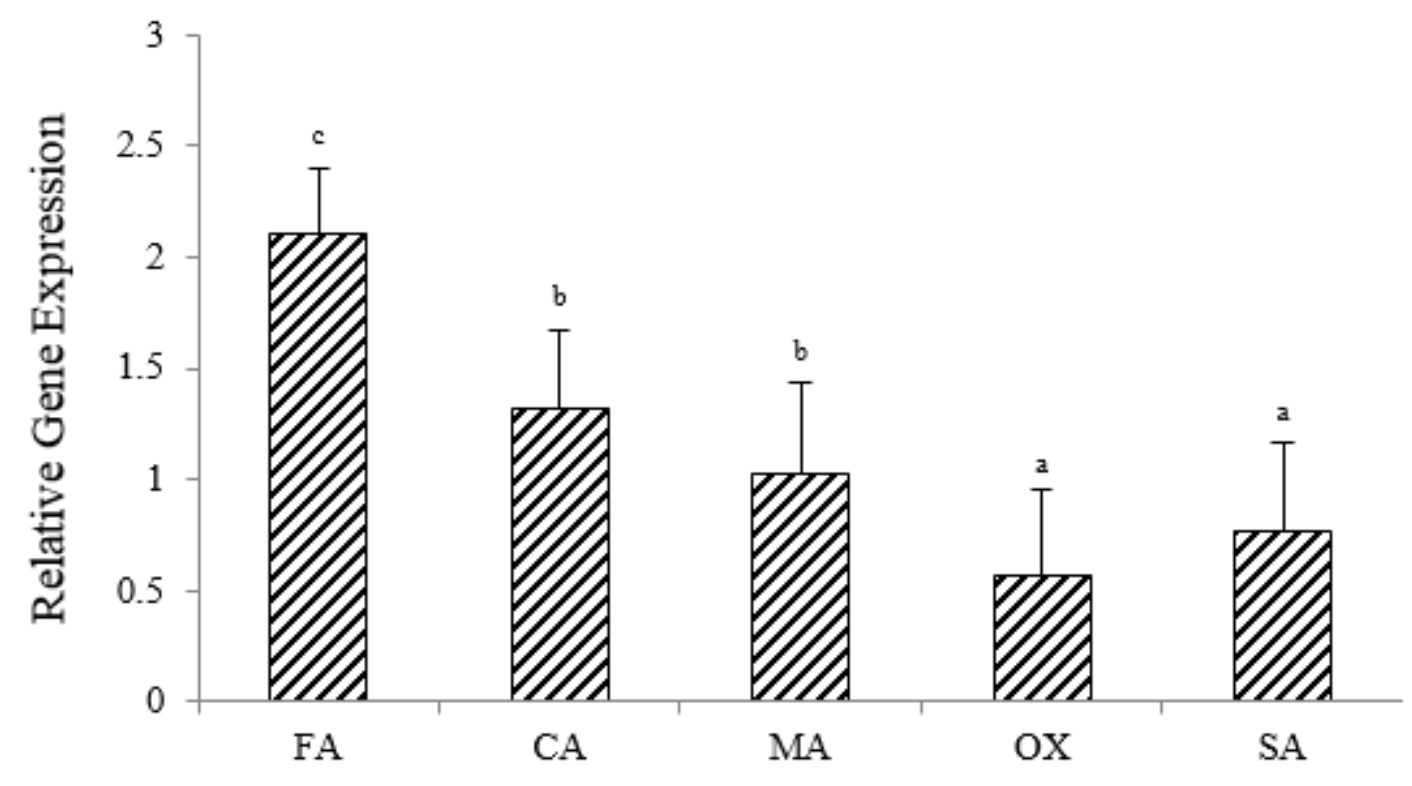

\section{Figure 6}

Effects of organic acids on the cheA gene transcript expression in Bacillus amyloliquefaciens subsp. plantarum YP1. Strain YP1 grown in NB medium was amended with citric acid (CA), fumaric acid (FA), malic acid (MA), oxalic acid (OX), and succinic acid (SA) at a final concentration of $50 \mu \mathrm{M}$. The data presented are the means \pm standard deviation (SD) of three independent replicates. Columns with different letters represent statistically significant differences for each gene according to Duncan's multiple range test $(p<0.05)$. 


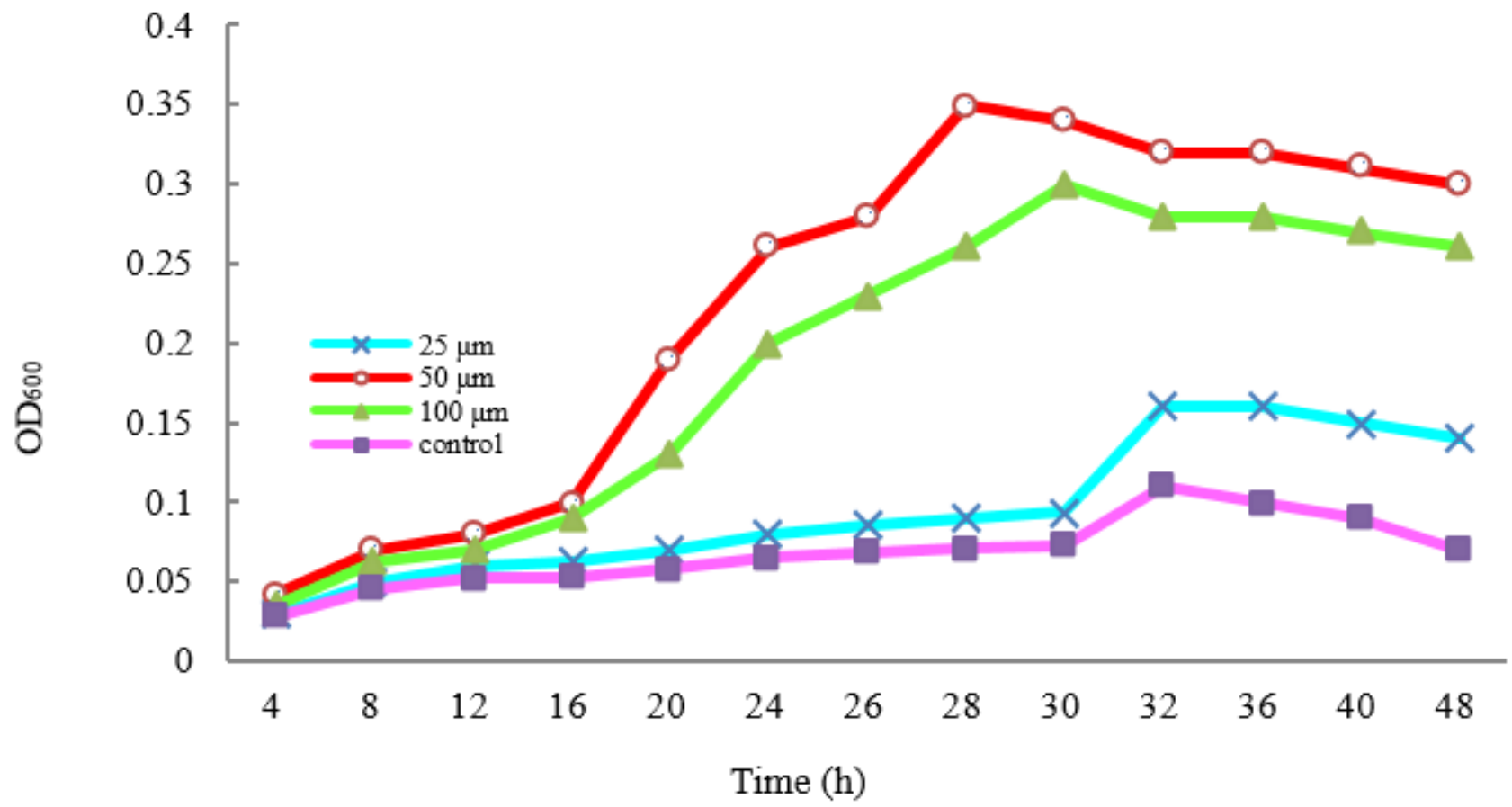

Figure 7

Effects of fumaric acid (FA) at different concentrations on the growth of B. amyloliquefaciens subsp. plantarum YP1. Control (Minimal medium, MM). The MM medium was supplemented with FA at final concentrations of 25,50 , and $100 \mu \mathrm{M}$. 


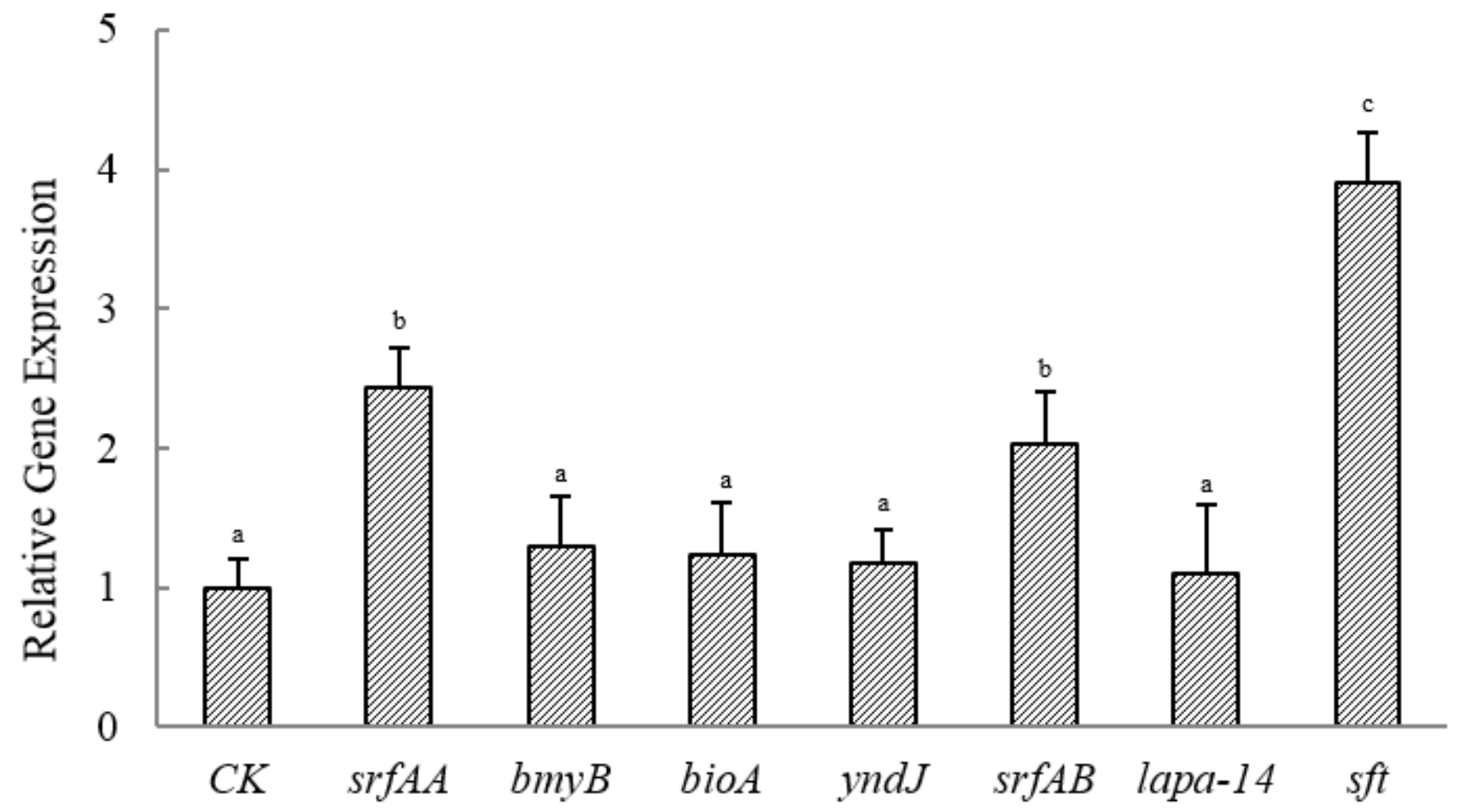

Figure 8

Effects of fumaric acid (FA) on the expression of biocontrol-related genes in Bacillus amyloliquefaciens subsp. plantarum YP1. Strain YP1 grown in NB medium without FA was used as CK to normalize the expressed value. NB medium was amended with FA at a final concentration of $50 \mu \mathrm{M}$. The data presented are the means \pm standard deviation (SD) of three independent replicates. Columns with different letters represent statistically significant differences for each gene according to Duncan's multiple range test $(p<0.05)$.

\section{Supplementary Files}

This is a list of supplementary files associated with this preprint. Click to download.

- SupplementaryMaterialsforAVL.docx 